\title{
Combustion characteristics of oxygenated fuels Ethanol -and Butanol- gasoline fuel blends, and their impact on performance, emissions and Soot Index
}

\author{
P. Anselmi, M. Matrat, L. Starck, F. Duffour \\ IFP Energies nouvelles
}

Copyright $\odot 2019$ SAE Japan and Copyright $\odot 2019$ SAE International

\begin{abstract}
Oxygenated fuels are studied in spark combustion engines because of their potentially positive impact on greenhouse emissions, and as part of alternative renewable fuels. Furthermore, engine test results position them as a promising lever to reduce engine-out emissions, and most notably, particles. This study focuses on oxygenated fuel Butanol, which is a potential output of recent developments on Algae and Cyanobacteria harvest process. Its blending into gasoline and application into spark ignition engines is investigated. Blending levels of $n$-Butanol and iso-Butanol have been proposed based on standard gasoline's octane number, RON, at two ethanol concentration levels, 10 and $25 \%$. Fuel blend impact on combustion, and on regulated and non-regulated emissions is analysed. Fuel knock resistance properties, RON and MON, determine the knocking tendencies for ethanol and butanol at $2000 \mathrm{rpm}$. However, test results highlight different knocking sensibility behaviour at higher engine speed. Emission results also illustrate a strong advantage of Butanol on particle mass emissions. Soot indices, that are conventionally used to quantify the impact of a fuel over particle emissions, are studied and confronted to results obtained on ethanol blends. The deviation in Particle Matter Indices obtained for butanol blends is analysed, on the basis of specific operating points. It highlights different particle emissions responses to the increase of oxygenates ethanol and butanol, not uniquely correlated to oxygen and aromatic concentration.
\end{abstract}

\section{INTRODUCTION}

Butanol fuels have become of increasing interest as alternative fuels when blended into gasoline. Several studies identify butanol as a product of algae and microalgae [1, 2], food waste [3] and gas waste $\left(\mathrm{CO}_{2}\right.$, $\mathrm{CO}, \mathrm{H}_{2}$ ) [4], and hence their production processes have a potential to reduce dependence on petroleum fuels, recycle carbon dioxide, and reduced greenhouse effects.

Butanol is present in four different isomers: $n$-butanol, iso-butanol, tert-butanol and s-butanol. Their physical and chemical properties vary quite significantly, and consequently their engine combustion behaviour may differ, as has been highlighted by Regalbuto et al. [5]. For example, the viscosity of iso-butanol almost doubles compared to n-butanol, and this property can contribute to affect the spray formation and the wall wetting within the combustion chamber. Three key combustion properties must be considered. Firstly, the laminar flame speed, mostly related to the high temperature fuel reactivity, is essential for the flame kernel development. The second parameter is related to the auto-ignition delay, as it is a first order factor on knocking behaviour in gasoline engines. Finally, the intermediate combustion products are of interest to apprehend the fuel effect on exhaust emissions. Sarathy et al. [6] reported the butanol isomers effects on these key combustion parameters based on an exhaustive review. A slight laminar flame speed increase is reported for $n$-butanol, compared to the branched isomers, all of whom have similar flame speed. The auto-ignition properties of the isomers are also quite different as highlighted by their respective octane numbers. The most reactive isomer under engine relevant conditions is $n$-butanol, due to an important contribution of the peroxy chemistry, favoured by the linear alkyl chain. The speciation at high temperature of these four isomers is related to complex reaction pathways, as emphasized by Sarathy et al. [6]. It underlines a strong contribution of light oxygenated species, such as formaldehyde, but also $\mathrm{C}_{2}$ to $\mathrm{C}_{4}$ intermediates including -but not limited to- several aldehydes: acetaldehyde, propanal, acetone or butanal and alcohols: ethanol, iso-propenol or 2-propenol. These data are mostly related to academic experimental measurements and provide some insight on the combustion effects of these isomers.

Considering butanol potential particle reduction, and its high knocking resistance for branched isomers, several studies have proposed butanol isomer blending to improve gasoline engine performance [7-9]. Of the four isomers, n-butanol is the most reported, where studies have been carried out with concentration ranging from 3 to $100 \%$, for indirect port-fuel injection systems (PI), and up to $30 \%$ with direct injection (DI). Other isomers investigated are iso-butanol, tert-butanol, and in less proportion, s-butanol. 
It has been demonstrated that the use of ethanol or iso-butanol enables to decrease soot emissions, attributed mainly to the increased oxygen content in the fuel [10]. Butanol is considered as a potential substitute to ethanol, as oxygenated blending component. Moreover, some results found in literature highlight the higher particle reduction of $n$-butanol as compare to ethanol, even if a lower $\mathrm{O} / \mathrm{C}$ ratio is obtained for the n-butanol/gasoline mixture, suggesting that other parameters are of interest [11]. However, some results have indicated an increase in particle numbers under certain levels of oxygenated concentration, or engine configurations [12, 13]. Tests have indicated that particle size distribution is also affected. For example, Costagliola [14] has compared ultra-fine $(<10 \mathrm{~nm})$ particle emissions of ethanol and butanol gasoline blends. Under low load operation, ethanol offers the strongest particle reduction, but at higher loads butanol shows an advantage on these emissions. Recent work on particle matter indices, to predict a fuel's behaviour over particle emissions, has been only recently extended to oxygenated fuels [15-17] but remains to be improved on the specific effects of each oxygenated compound.

Oxygenated fuels can also impact carbon monoxide (CO), unburned hydrocarbons (UHC) and nitrogen oxide (NOx) emissions. Results presented by Karavalakis et al. [13], on different vehicles, driving cycles with ethanol and butanol blends; show a reduction of UHC for spray guided engines, for all blends. Generally, the reduction becomes stronger as the oxygenate concentration increases. Due to high $\mathrm{O} / \mathrm{C}$ ratios, oxygenated fuels can contribute to limit UHC emissions. Moreover, results obtained by Lattimore et al. [11] on a DI spray guided (SG) engine, showed that the decrease obtained with ethanol is stronger than butanol (at same concentration), despite the fact that ethanol presents a longer combustion duration and lower flame temperature. This suggests that the oxygen over carbon $(\mathrm{O} / \mathrm{C})$ ratio is of first order over unburned emissions. It should be noted that tests by Chen et al. [17] tests on a wall guided (WG) engine found a different result when n-butanol was blended to gasoline: An increase of unburned emissions is obtained, probably enhanced by increasing fuel wall wetting of WG combustion chambers. It is likely that under this less favourable engine conditions, butanol's higher viscosity has an impact over wall wetting that exceeds the advantages of the higher $\mathrm{O} / \mathrm{C}$ ratio.

The fuel blend's impact over combustion is key for nitrogen oxides emissions. Three main pathways exist to explain NOx formation : (1) Thermal NO: It is related to the nitrogen reaction with oxygen at high temperature in the flame. A high temperature is required to exceed the energy barrier related to the strong $\mathrm{N}_{2}$ bond energy; (2) Prompt NO: Highly reactive species from fuel decomposition are reacting with nitrogen from air providing an alternative route to nitrogen oxides formation; (3) Fuel NO: In this case, the nitrogen oxides are mainly arising from the fuel composition itself through, for example, nitrogen containing additives. NOx emissions from alcohol additions will potentially affect the first two. The key parameters that must be considered in these cases are the temperature, the oxygen availability, and the reaction intermediates arising from fuel decomposition. An increase of nitrogen oxides emissions could be expected considering the higher $\mathrm{O} / \mathrm{C}$ ratio. Indeed, it provides oxygen locally which could contribute to enhance the NOx formation. However, literature [11, 17] describes a decrease in nitrogen oxides, a tendency which indicates that other parameters are of interest. Some publications have demonstrated that the combustion duration can decrease for $n$-butanol/gasoline blends. This contributes to the decrease of the exhaust temperature and extends the post-oxidation time [17]. Other NOx formation routes, such as the prompt NO, remains to be investigated to better characterize butanol effect.

The use of oxygenated fuels also affects unregulated emissions $[17,18]$. Indeed, the literature indicates the increase in oxygenated emissions when alcohols are incorporated into gasoline. Storey et al. [18] measured the emissions of aldehydes when iso-butanol $(48 \% \mathrm{vol})$ and ethanol (30\%vol) are blended to gasoline, and identifies butyraldehyde $\left(\mathrm{C}_{4} \mathrm{H}_{9} \mathrm{O}\right)$ as the main contributor of oxygenated $\mathrm{C}_{4}$. This tendencies have been confirmed by Karavalakis et al. [10] with ethanol blends (up to $30 \% \mathrm{vol}$ ) and iso-butanol blends (up to $34 \%$ vol). Both studies are carried-out on vehicle driving cycles.

These works suggest that butanol behaviour is strongly dependent on the engine technology, e.g. injection system and compression ratio, as well as butanol blending and isomer. A study on a state of the art engine, under enhanced aerodynamics and direct injection seems necessary to clarify behaviour of butanol. Moreover, analysis comparison of major butanol isomers, iso- and n-butanol, against ethanol blends, under equivalent operating conditions will also delineate fuels' properties and behaviour. The work presented comprises a comparison of engine performance, knock behaviour, regulated emissions, aldehyde emissions analysis, and particle matter index correlation, measured over for a large engine operating region.

\section{FUEL MATRIX}

The analysis presented is based on oxygenated and gasoline blends at set Research Octane Number (RON), where the effect of blending of butanol isomers, iso-butanol and $n$-butanol with gasoline fuels is studied, and compared to ethanol blends. For this, two RON targets were defined. First blend group was set at RON 95, as per regulation limit EN 228, where the reference fuel contains $10 \% \mathrm{vol}$ of ethanol. The second blend group is set at RON of 101 , resulting from blend of $25 \%$ vol of ethanol, with the objective to investigate the potential of high RON fuel, and the comparison of butanol's knock resistance to that of ethanol's. The base gasoline fuel is a RON91 standard fuel, used for all blends. Mixtures of 
iso-butanol or n-butanol for these set RON values where established for comparison, as listed:

1. RON 95 blends, as per minimum value required by specification EN228:

- E10: RON95, $10 \%$ vol, ethanol and $90 \%$ vol gasoline RON 91, as per standard European RON 95 gasoline.

- iBut20: RON95, iso butanol $20 \%$ vol, and $80 \%$ vol gasoline RON 91.

- nBut55: RON95, $55 \%$ vol n-butanol and $45 \%$ vol gasoline RON 91.

2. Higher RON 101, for comparison of $25 \% \mathrm{vol}$ ethanol blend to equivalent butanol blend:

- E25: RON101, $25 \%$ vol ethanol and $75 \%$ vol gasoline RON 91.

- iBut45: RON101, iso butanol $45 \%$ vol and $55 \%$ vol gasoline RON 91.

\section{FUEL BLEND PROPERTIES}

The fuel blends have been analysed and their measured properties are listed in Table 1. Butanol and $25 \%$ vol ethanol blends, have an increasing oxygen concentration and a reduced Lower Heating Value (LHV) as compared to reference E10. It is thus expected for these fuels to present a higher volumetric fuel consumption. Concerning European regulation, the blends' oxygen concentration exceeds current limit of $3.7 \% \mathrm{~m} / \mathrm{m}$, and maximum oxygenated concentration, of $15 \%$ vol for butanol, and $10 \%$ vol for ethanol. Nevertheless, the blends allow to study the impact of butanol blending as improvers of lower octane rating gasoline RON91.

Density and vapour pressure (DVPE) values are within, or close to regulation limits of 720 to $775 \mathrm{~kg} / \mathrm{m} 3$, and 45 to $70 \mathrm{kPa}$, respectively. Exception is found for nBut55, whose DVPE is below limits. Another characteristic of oxygenated fuels ethanol and butanol is the increase of heat of vaporization. This property enhances a reduction of air-fuel mixture temperature, which can have a negative impact under low load and cold operation, whilst it can improve knock resistance. Under engine operating conditions, the total heat of vaporization (HOV) will be dependent on the fuel mass injected. Correction of the heat of vaporization, at constant energy introduced, is represented in Figure 1, as a ratio to reference fuel E10. Butanol blend iBut20 HOV's is equivalent to reference fuel E10. Ethanol $25 \%$ vol blend, E25, introduces an increase of $5 \%$ of the HOV. Blending of n-butanol, at $55 \%$ vol, nBut55, results in an increased HOV, by $10 \%$. Iso-butanol at $45 \%$ vol, iBut 45 , also presents an increased HOV. The increment is of $9 \%$ compared to E10, and of $5 \%$ when compared to E25.
Table 1. fuel properties of blend matrix.

\begin{tabular}{|c|c|c|c|c|c|c|}
\hline & & E10 & E25 & $\begin{array}{l}\text { iBut } \\
20 \\
\end{array}$ & iBut 45 & nBut 55 \\
\hline $\begin{array}{l}\text { Carbon } \\
\text { content C }\end{array}$ & $\begin{array}{c}\% \\
\text { mass }\end{array}$ & 82.9 & 77.5 & 81.9 & 76.3 & 74.1 \\
\hline $\begin{array}{l}\text { Hydrogen } \\
\text { content } \mathrm{H}\end{array}$ & $\begin{array}{c}\% \\
\text { mass }\end{array}$ & 13.4 & 13.4 & 13.5 & 13.5 & 13.5 \\
\hline $\begin{array}{l}\text { Oxygen } \\
\text { content } \mathrm{O}\end{array}$ & $\begin{array}{c}\% \\
\text { mass }\end{array}$ & 3.7 & 9.1 & 4.6 & 10.2 & 12.4 \\
\hline RON & - & 95.5 & 101.1 & 95.6 & 100.5 & 95.4 \\
\hline MON & - & 86.3 & 88.2 & 85.6 & 87.2 & 84.0 \\
\hline Sensitivity & - & 9.2 & 12.9 & 10 & 13.3 & 11.4 \\
\hline $\begin{array}{l}\text { Viscosity, } \\
20^{\circ} \mathrm{C}\end{array}$ & $\mathrm{mm}^{2} / \mathrm{s}$ & 0.584 & 0.737 & 0.723 & 1.309 & 1.502 \\
\hline Density & $\mathrm{kg} / \mathrm{m}^{3}$ & 742 & 750 & 749 & 765 & 774 \\
\hline $\begin{array}{l}\text { Vapour } \\
\text { pressure } \\
\text { DVPE }\end{array}$ & $\mathrm{kPa}$ & 64 & 60 & 51 & 44 & 40 \\
\hline $\begin{array}{l}\text { Lower } \\
\text { heating } \\
\text { value LHV }\end{array}$ & $\mathrm{MJ} / \mathrm{kg}$ & 40.87 & $\begin{array}{l}38.65 \\
(-5 \%)^{*}\end{array}$ & 40.81 & $\begin{array}{l}38.08 \\
(-7 \%)^{*}\end{array}$ & $\begin{array}{l}37.30 \\
(-9 \%)^{*}\end{array}$ \\
\hline $\begin{array}{l}\text { Vaporizat. } \\
\text { (HOV) }\end{array}$ & $\mathrm{kJ} / \mathrm{kg}$ & 2994 & 3147 & 2993 & 3273 & 3302 \\
\hline
\end{tabular}

* variation with respect to reference E10.

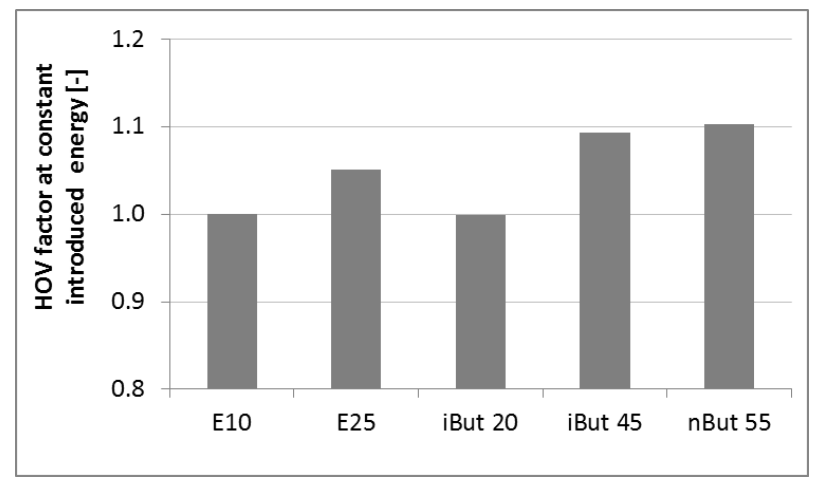

Figure 1. Heat of vaporization (HOV) ratio, at constant introduced energy.

Distillation curves are presented in Figure 2. As compared to reference E10, high ethanol fuel E25 presents a very similar distillation curve up to $40 \% \mathrm{vol}$ distillate, and $71^{\circ} \mathrm{C}$. However, for E25, a fast distillation is maintained up $70 \% \mathrm{vol}$ of distillate. This point is reached at $75^{\circ} \mathrm{C}$, against $108^{\circ} \mathrm{C}$ for E10. Above $80 \%$ vol distillation, the E25 distillation curve re-joins the $\mathrm{E} 10$ curve, at an approximate $10^{\circ} \mathrm{C}$ temperature reduction. As a consequence, the regulation limit E100 is exceeded by reaching $77 \%$ vol, against maximum allowed value of $71 \%$ vol. This characteristic will possibly present advantages of fuel vaporization and mixture formation. Butanol blends distillation up to $40 \% \mathrm{vol}$ takes place at higher temperatures compared to E10. The temperature gap increases with the concentration of butanol, regardless of the isomer. At $70{ }^{\circ} \mathrm{C}$ (regulation EN228, E70), distillation has reached $14 \%$ vol for iBut20, $9 \%$ vol for iBut 45 and $7 \%$ vol for nBut55. These concentrations are lower than that of reference fuel E10, whose distillation volume is $36 \%$; and they are 
bellow regulation limits, $20-50 \%$ vol. However, for iso-butanol, fuel distillation is fast between 90 and $100{ }^{\circ} \mathrm{C}$. At $100^{\circ} \mathrm{C}$ (regulation EN228, E100), distillation has reached a volume of $75 \%$ and $50 \%$ for iBut20 and iBut45, against $54 \%$ vol for E10. At $130{ }^{\circ} \mathrm{C}$ (regulation EN228, E130), iBut20 and iBut45 have reached $86 \%$ and $92 \%$ vol distillate, respectively, whilst reference $\mathrm{E} 10$ has a $83 \%$ vol distillates. Similarly, nBut55 shows a fast distillation region within temperatures of 100 to $120^{\circ} \mathrm{C}$, having fully evaporated at $122^{\circ} \mathrm{C}$. For butanol blends, if higher temperatures are required for light compounds to evaporate, the faster evaporation of heavier compounds, and the higher oxygen content, could be favourable to reduce particle and UHC emissions, namely under warmer engine conditions.

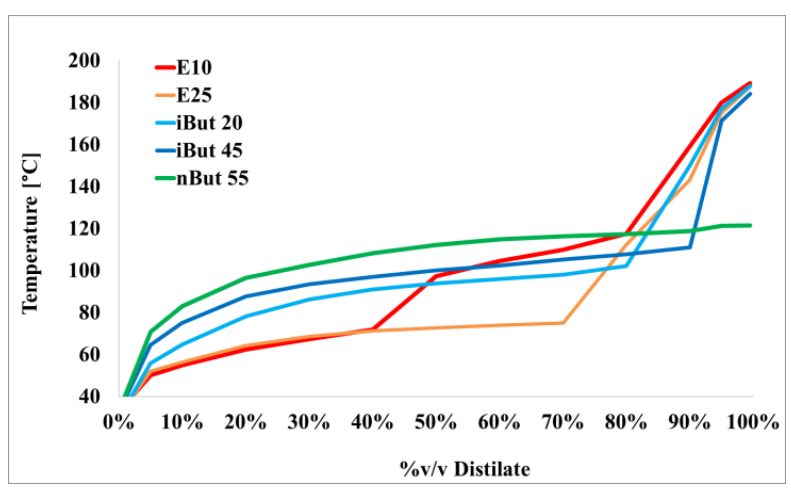

Figure 2. Distillation curves for the five fuels tested

\section{ENGINE DESCRIPTION AND MEASUREMENTS}

The engine used for testing is a single cylinder direct injection engine. The injector is centrally mounted to reduce cylinder wall wetting. The tumble is high and reaches a mean value of 1.4 [19]. Increased engine aerodynamics is known to contribute to combustion acceleration, improve mixing and reduced particle formation. The major engine technical characteristics are presented in Table 2. Tests were carried out at stabilized conditions, under warm operation at $90^{\circ} \mathrm{C}$ oil and coolant temperature. A cold operation campaign was also included. These tests were conducted under stabilized engine conditions, and fluids' temperature regulated at 30 and $50^{\circ} \mathrm{C}$, for both oil and coolant.

Engine cylinder pressure was measured using an AVL cooled sensor, centrally mounted. The standard deviation of the sensor was measured to be below $0.2 \%$. To ensure that no contamination between fuels takes place during testing transitions, fuel filters were changed with each new fuel tested, and a purging time was imposed. A repeatability protocol has been set to control the variability, and detect external perturbations. Moreover, the reference fuel was tested in three different phases, at the beginning, mid and end of the experimental campaigned. These results validated the absence of derivation on engine operation or measuring equipment. Engine-out emissions were measured using an AVL AMA i60
FTIR exhaust gas analyser. Taking into account the variable alcohol content of the fuels, unburned hydrocarbons (UHC) and methane $(\mathrm{CH} 4)$ emissions are corrected for oxygenated fuels, according to Wallner et al [20]. These correlations have been validated for butanol and ethanol blends.

Particle mass emissions are measured using an AVL 415S smoke meter, and particle numbers are measured with a DMS500, from $5 \mathrm{~nm}$ to $1000 \mathrm{~nm}$. Exhaust gases have been diluted as recommended by DMS500 measurement equipment, and no gas stripper has been included. Therefore, particle number presented here include volatile particles, as opposed to standard cycle particle measurement. Particle mass is estimated based on smoke meter measurement.

Maximum standard deviation of the different measurements are indicated in the Table 3 . It results from the uncertainties of the measuring equipment and the engines' operation repeatability. It is obtained from analysis at 4 bar and 13 bar IMEP.

Table 2. Single-cylinder engine characteristics.

\begin{tabular}{|l|l|}
\hline Displaced volume & $410 \mathrm{~cm}^{3}$ \\
\hline Stroke & $93 \mathrm{~mm}$ \\
\hline Bore & $75 \mathrm{~mm}$ \\
\hline Compression ratio & $12.0: 1$ \\
\hline Number of Valves & 4 \\
\hline Exhaust Valve Close & $10^{\circ}$ BTDC @ $0.7 \mathrm{~mm}$ lift \\
\hline Inlet Valve Open & $-10^{\circ}$ BTDC @ $0.7 \mathrm{~mm}$ lift \\
\hline Start of Injection SOI & 290 to $310^{\circ} \mathrm{V}$ optimised \\
\hline
\end{tabular}

Table 3. Standard deviation of the experimental measurements performed.

\begin{tabular}{|ll|}
\hline Indicated fuel consumption ISFC [g/kWh] & $1.00 \mathrm{~g} / \mathrm{kWh}$ \\
\hline Indicated hydrocarbons $\mathrm{HC}[\mathrm{g} / \mathrm{kWh}]$ & $0.3 \mathrm{~g} / \mathrm{kWh}$ \\
\hline Indicated carbon monoxide CO [g/kWh] & $0.5 \mathrm{~g} / \mathrm{kWh}$ \\
\hline Indicated nitrogen oxide NOx [g/kWh] & $0.2 \mathrm{~g} / \mathrm{kWh}$ \\
\hline Methane $\mathrm{CH} 4$ [ppm] & $6 \mathrm{ppm}$ \\
\hline Particles number [N/cc] & $<23 \mathrm{nm:} 1.2 \mathrm{E06}$ \\
\hline Particle mass [g/kWh] & $>23 \mathrm{~nm}: 1.3 \mathrm{E05}$ \\
\hline
\end{tabular}

\section{RESULTS}

Results for E25 and butanol blends, iBut20, iBut 45 and nBut55, are compared to reference fuel E10. Engine tests were conducted at two engine speeds, $2000 \mathrm{rpm}$ and $4000 \mathrm{rpm}$, and engine load sweep. Load was varied from 1 bar to full load. Maximum load was limited by the maximum allowed cylinder pressure, maximum allowed intake pressure and 
exhaust temperature. Results are presented in different subsections, dedicated to the combustion efficiency and fuel consumption, full load, engine-out emissions, cold operation, particle matter index analysis, and aldehyde emissions.

\section{COMBUSTION TIMING}

In this section, results are presented with emphasis on fuel consumption, combustion timings, and knocking tendency. Results are analysed at 2000 and $4000 \mathrm{rpm}$

\section{Engine operation at $2000 \mathrm{rpm}$}

Figure 3 presents fuel consumption (above) and combustion efficiency (bellow), at $2000 \mathrm{rpm}$ and variable engine charge. The percentage of variation of the Indicated Specific Fuel Consumption (ISFC), with respect to the reference fuel $\mathrm{E} 10$, is shown in middle position. At low load, and up to 9 bar IMEP (Indicated Mean Effective Pressure), combustion phasing Mass Fraction Burned $50 \%$ (MFB50) is set at constant optimum angle. In this load range, variations of the ISFC can be observed for higher ethanol fuel, E25 and most butanol blends. The results indicate a mean increase of $5 \%$ of the fuel consumption for E25; no variation for iBut20; an increase of $5 \%$ for iBut45; and $8 \%$ for nB55. Analysis of the combustion efficiency shows reduced impact of the fuel blend over the combustion development, where variations are under $1 \%$ efficiency, indicating that fuel consumption variations are mainly driven by the fuel blends' low heating value and density. Moreover, the consumption increase is comparable to the blends' heating value reduction, indicated in Table1. Other authors have also reported little impact of ethanol (10 to $85 \% \mathrm{vol}$ ) and butanol (10\%vol) on the combustion development [12]. Figure 4 presents relative efficiency variations with respect to $\mathrm{E} 10$ in the low load area, where combustion is at constant MFB50. The error bar has been integrated in grey. It shows that higher concentration of iso-butanol, iBut45, outstands from error deviation, and allows a mild increase of the efficiency, between $0.3 \%$ and $0.6 \%$. All butanol blends shift towards a slight combustion improvement at low IMEP of 2 bar. This tendencies are encouraged by a slightly faster combustion, increased maximum heat release rate, and better combustion stability. An example of mass fraction burned at 2 bar IMEP, Figure 5, shows the advanced combustion for iso-butanol and higher total fraction burned as compared to reference fuel. The reduced combustion instability of iBut45 and nBut55 is also represented.

For mid to high load operation points, i.e. from 9 bar IMEP, combustion phasing MFB50 is driven by the fuel's knock resistance. As a consequence, deviations of the fuel consumption can be observed, increasing for a stronger knocking behaviour and late combustion phasing, Figure 6. Blends at RON 95, iBut20 and nBut55, show a combustion phasing similar to that of reference E10. Fuels at RON 101, E25 and iBut45, present similar phasing, and are advanced by circa $10^{\circ} \mathrm{CA}$ with respect to $\mathrm{E} 10$. As a consequence of this improved phasing, fuel consumption is reduced by $4 \%$ for E25, and by $2 \%$ for iBut45 in the 16 to 18 bar IMEP load range. Combustion phasing is strongly related to the fuels' RON and MON properties.

Several studies [21-23] have demonstrated that knocking limited spark advance and combustion phasing MFB50, are strongly correlated to the fuels Octane Index (OI). The $\mathrm{Ol}$ is determined as a function of the fuel's RON and Sensibility (S), according to Equation 1. Where the fuel Sensitivity, $S$, is calculated as the difference between RON and MON, and $K$ is dependent on the engine's operating point.

$$
O I=R O N-K \times S
$$

Equation 1
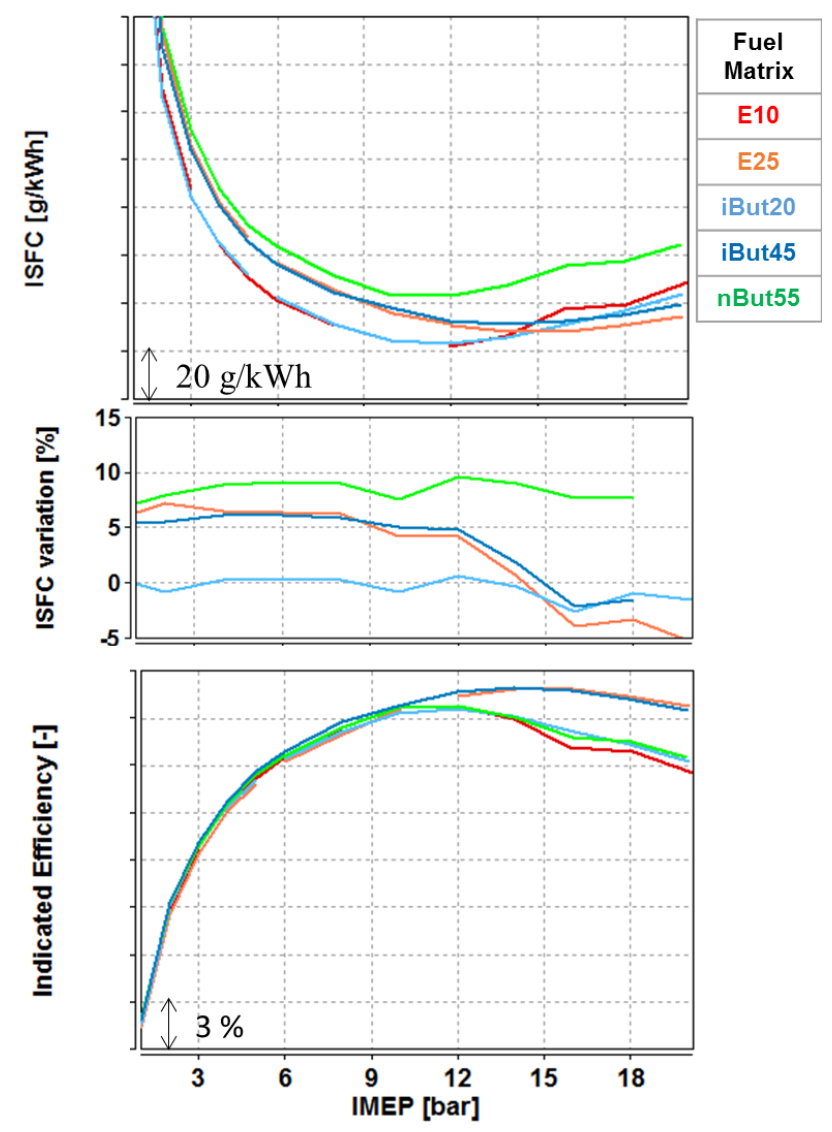

Figure 3 (above) ISFC, (middle) percentage variation of the ISFC with respect to reference E10, and (bellow) indicated efficiency for oxygenated fuel matrix at 2000 rpm, IMEP sweep.

Under some conditions, $\mathrm{K}$ can present a negative value. In this case, the fuels $\mathrm{Ol}$ is increased by a stronger sensibility and higher RON. For positive $\mathrm{K}$ values the $\mathrm{OI}$ is improved by a stronger RON and MON values. $\mathrm{K}$ tends to decrease with engine charge.

At $2000 \mathrm{rpm}$, operating points under knocking conditions, 12, 14, 16 and 18 bar IMEP, have been analysed based on the fuel's RON and OI. Figure 7, 
upper image, indicates the operating point knock limited MFB50 as a function of RON. A trend line has been obtained, and the coefficient of determination are indicated in the figure for each operating point. It shows that a good modelling can be recorded between the fuel's knock-limited MFB50 and the RON value. Comparison of combustion phasing MFB50 against the $\mathrm{Ol}$ is illustrated in Figure 7, lower image.

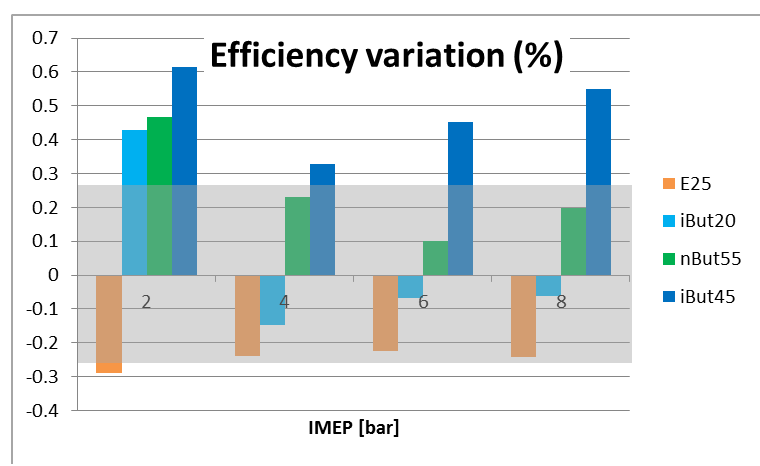

Figure 4. Combustion efficiency with respect to reference fuel E10, at 2000 rpm. Error bar reported.

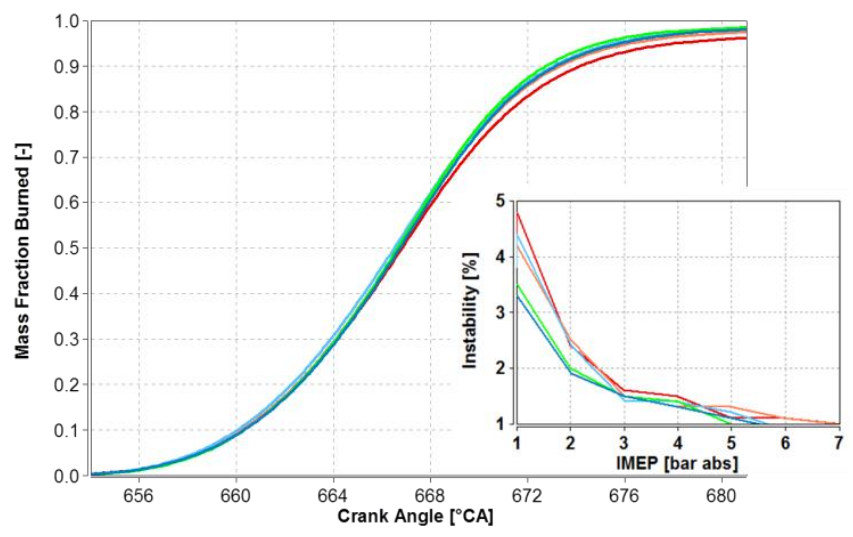

Figure 5. Mass fraction burned at 2000 rpm, 2 bar IMEP.

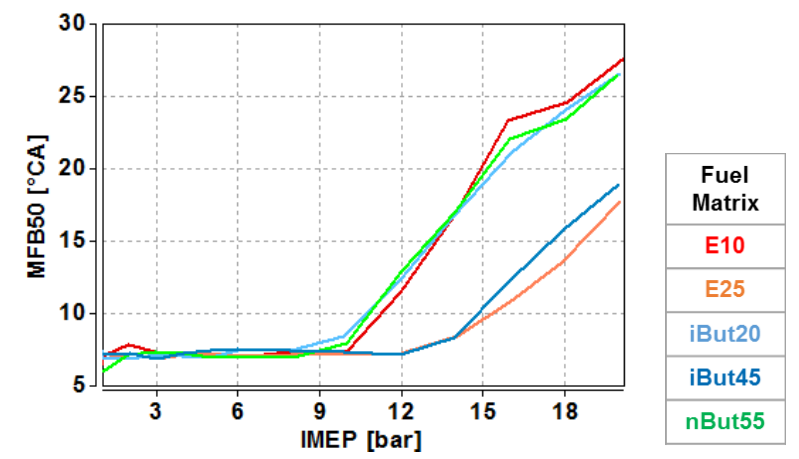

Figure 6. Combustion phasing MFB50 at 2000 rpm charge sweep.

Correlation against $\mathrm{OI}$ is slightly improved as compared to RON correlation. Resulting $\mathrm{K}$ values are listed in Table 4. It shows a reduction of $\mathrm{K}$ as the load increases, having negative values for 16 and 18 bar IMEP. The results indicate that for this engine operating speed, RON is a first order fuel property for the characterization of the knocking behaviour. The sensitivity $S$ influences knocking resistance in a second degree, having opposing influence as a function of the engine load. At mid load, lower sensitivity (higher MON) would reduce knock appearance, and as load increases -16, 18 bar IMEPa stronger sensitivity would profit knock resistance (lower MON, at same RON). The slightly stronger sensitivity $S$ of iBut20 and nBut55 increases the knock resistance, as can be observed on the MFB50 at 16 and 18 bar IMEP. At 12 bar IMEP, operating point for which $\mathrm{K}$ value is positive, iBut20 and $\mathrm{nBut} 55$ present a retarded combustion phasing. The strong MFB50 to Ol correlation obtained for all fuel blends indicate that knocking behaviour of butanol fuel blends is comparable to that of ethanol blending. That is, at $2000 \mathrm{rpm}$ ethanol and butanol's knocking resistance are related in a comparable manner to the RON and MON properties.

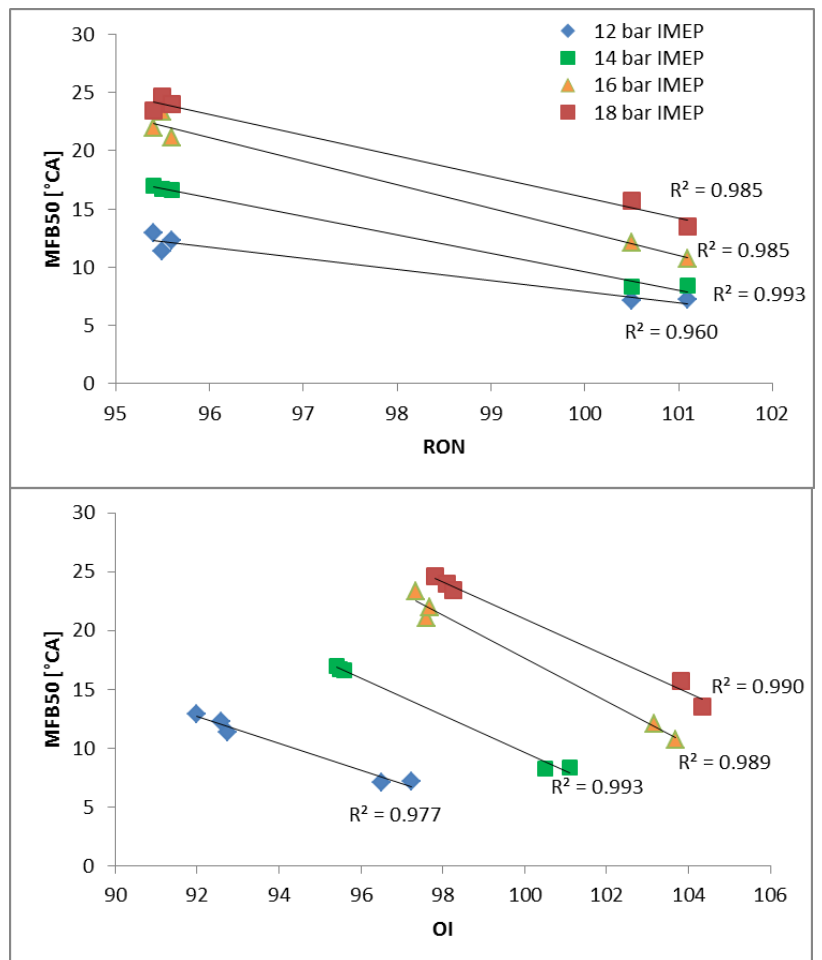

Figure 7. MFB50 as a function of RON and Ol at 12, 14, 16 and 18 bar IMEP. Ethanol and butanol blends, at 2000 rpm.

\begin{tabular}{ll} 
& K value \\
\hline 12 bar IMEP & 0.3 \\
14 bar IMEP & 0.04 \\
16 bar IMEP & -0.2 \\
18 bar IMEP & -0.25
\end{tabular}

Table 4. K value for OI correlation, 2000 rpm.

The heat of vaporization is another property of ethanol fuel blends having an impact over knock appearance. Works by Farrell et al. [24] on knocking correlation to fuel properties have indicated that RON and Sensibility are the most significant magnitudes characterizing a fuel. A stronger heat of vaporization would cause a reduction of the gas temperature 
before combustion and hence increases the auto-ignition delay. Comparison of ethanol and butanol blends show that at same energy introduced (Figure 1), the heat of vaporization increases by $10 \%$ for nBut55 with respect to E10, and by $5 \%$ for iBut45 with respect to E25. This magnitude increase of heat of vaporization of iBut45 and nBut55 does not seem to have a significant effect on the knocking tendency.

\section{Engine operation at $4000 \mathrm{rpm}$}

Results at $4000 \mathrm{rpm}$ are presented in Figure 8. At low load operation, 2 to 4 bar IMEP, combustion efficiency is comparable between the different fuel blends, and fuel consumption variations are driven by the blends lower heating value. Combustion duration analysis indicates that for nBut55 the total combustion duration is reduced by up to $0.5^{\circ} \mathrm{CA}$, as illustrated in Figure 9 . iBut45 shows a reduction of the combustion duration only at very low load, 1 and 2 bar IMEP. Other studies on butanol combustion have indicated faster burning rates and reduced delay for butanol fuels [11, 25]. In this study, the characteristic is only evidenced at low loads.
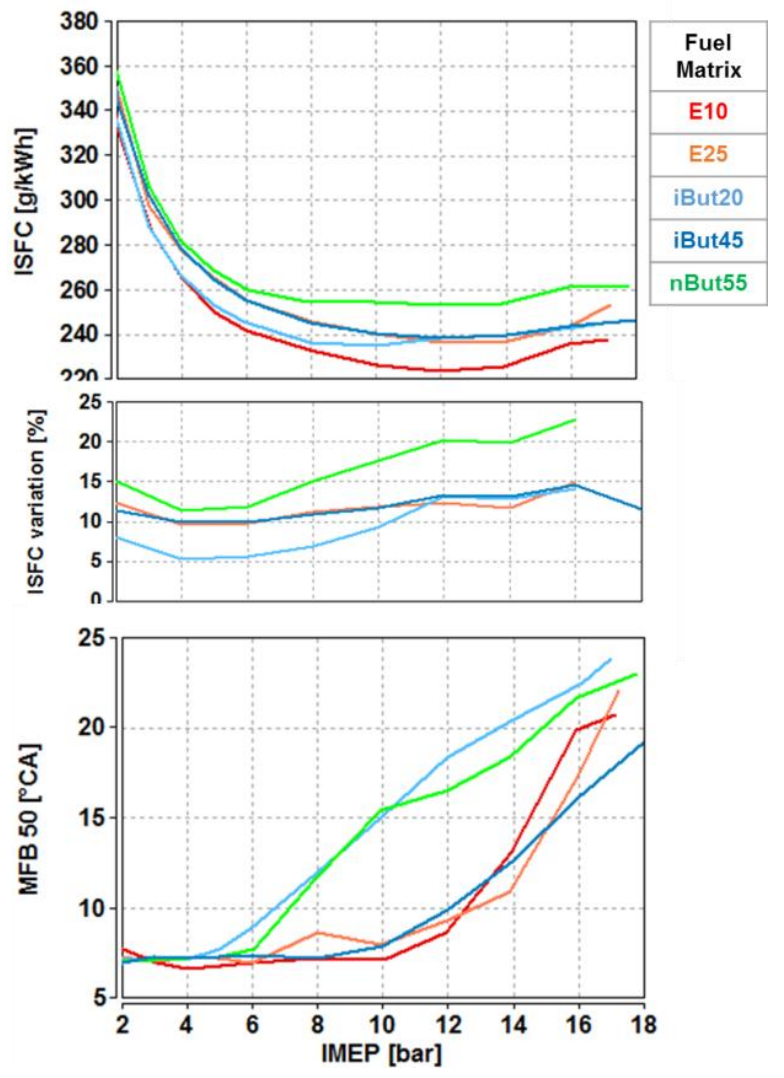

Figure 8. (above) ISFC, (middle) percentage variation of the ISFC with respect to reference E10, and (bellow) combustion efficiency for oxygenated fuel matrix at 4000 rpm, IMEP sweep.

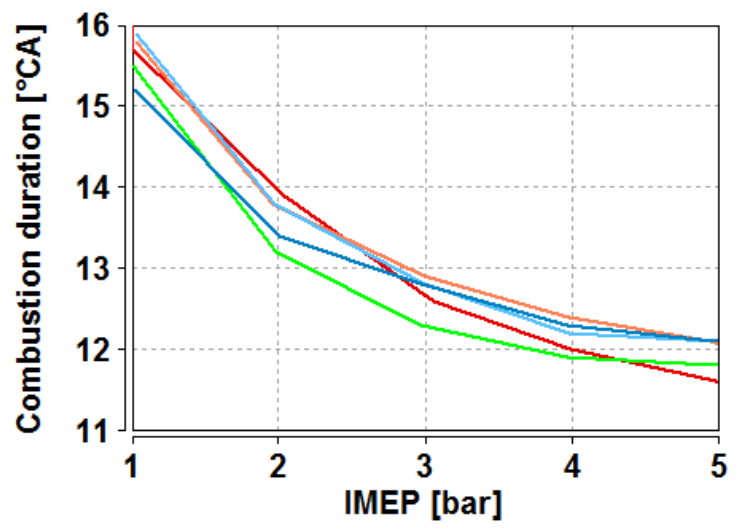

Figure 9. Combustion duration (MFB90-MFB10) at $4000 \mathrm{rpm}$.

From 6 bar IMEP, a strong knocking tendency is observed for blends iBut20 and nBut55, resulting in a delayed combustion phasing. Combustions phasing of E10 corresponds to normal phasing for this engine at RON 95. For the other RON 95 fuels, results indicate that at higher engine speed the knocking event is intensified for butanol fuels, having lower MON. However, for high load operation, 14 and 16 bar IMEP, nBut55 presents better combustion phasing than iBut20. It is possible that the slightly faster combustion of $n$-butanol is advantageous against the delay time for auto-ignition to develop. nBut55 could also be favoured by an increased HOV. Comparison of RON101 fuels, E25 and iBut45, suggests a reduced knocking event for iBut45, namely at 16 and 18 bar IMEP. This fuel blend presents slightly lower RON, higher sensitivity, and higher HOV. Moreover, butanol blends' delayed MFB50 shows a slower decline than ethanol blends, as engine load increases above 14 bar IMEP. Analysis of the knock limited combustion phasing MFB50, with respect to $\mathrm{OI}$, is illustrated in Figure 10. The coefficients of determination have been presented for each operating point. The results indicate an inferior fit, between 0.56 and 0.68 , namely for loads 10,12 , 14 bar IMEP. An improvement is obtained at high load of more than 16 bar IMEP. These results indicate that, unlike findings at $2000 \mathrm{rpm}$, at higher speed of $4000 \mathrm{rpm}$, the knocking tendency of butanol blends differ from that of ethanol blends, with respect to the RON and Sensitivity properties. Study by Szybist and Splitter [26] has also compared the knock behaviour of fuels at similar RON, showing that good correlation can be obtained between the knock limited combustion phasing MFB50 and the OI. This correlations has also been presented by Farrell et al. [24] and applied to n-butanol and iso-butanol fuels, amongst other fuels. However, the results presented by Szybist et al. have been correlated to $2000 \mathrm{rpm}$ operating conditions, while little literature has been found for high speed conditions. 


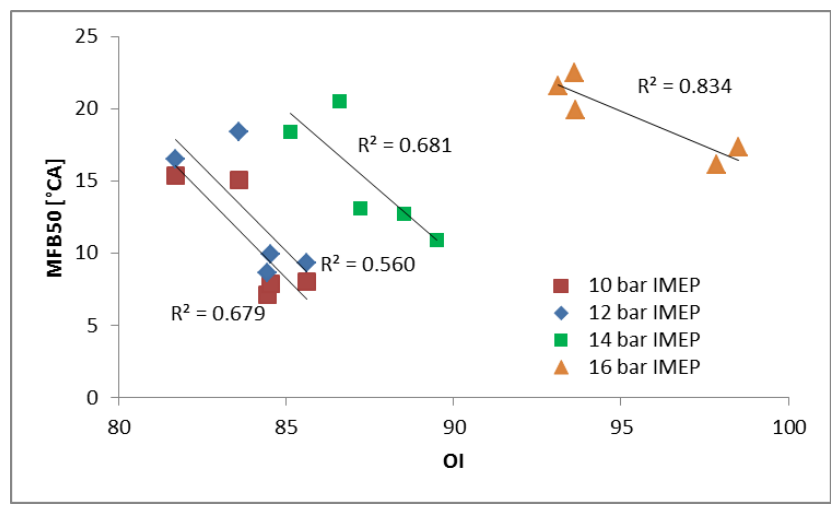

Figure 10. MFB50 as a function of Ol for $10,12,14$, and 16 bar IMEP, for ethanol and butanol blends, at 4000 rpm.

Table 5. K value for Ol correlation, $4000 \mathrm{rpm}$.

\begin{tabular}{lc} 
& K value \\
\hline 10 bar IMEP & 1.2 \\
12 bar IMEP & 1.2 \\
14 bar IMEP & 0.9 \\
16 bar IMEP & 0.2
\end{tabular}

Comparison of maximum load at 2000 and $4000 \mathrm{rpm}$ is represented in Figure 11. It shows that at $2000 \mathrm{rpm}$ the evolution is mainly determined by the RON number increase. A RON of 101 allows improving engine torque by close to $8 \%$, against RON 95.5. At $4000 \mathrm{rpm}$, butanol fuels iBut 45 presents an optimized combustion phasing, and thus a potential maximum load increase of $10 \%$ could be obtained. Because of nBut55's faster combustion, a lower exhaust temperature is obtained at same IMEP, that can be exploited towards an increase maximum torque, estimated to $2 \%$.

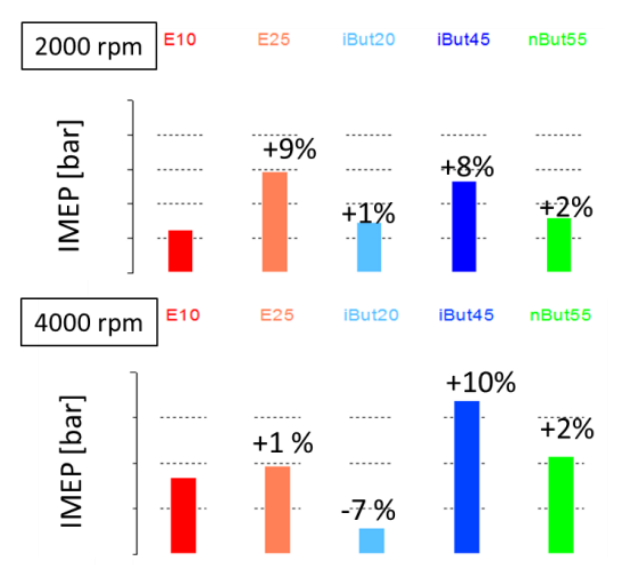

Figure 11. Full load IMEP at 2000 and 4000 rpm.

\section{EMISSIONS}

Primary engine-out emissions, NOx, UHC, $\mathrm{CO}$ and $\mathrm{CH} 4$ are very similar within the fuel matrix tested. Results at $2000 \mathrm{rpm}$ are illustrated in Figure 12. The most notable impact observed is a reduction of $\mathrm{CO}$ emissions for high Butanol blends, iBut45 and nBut55. $\mathrm{CO}$ emissions are reduced by up to $5 \mathrm{~g} / \mathrm{kWh}(28 \%)$ between 6 and 16 bar IMEP. The reduction is highest for iBut45. E25 also allows a reduction of $\mathrm{CO}$ emissions at higher loads; above 10 bar IMEP. It is likely that the higher oxygen concentration favours $\mathrm{CO}$ oxidation. UHC emissions are similar through most of the operating range, indicating a possible balance between the favourable reduced $\mathrm{O} / \mathrm{C}$ ratio of oxygenated fuels, and the higher fuel consumption and viscosity. However, at low loads, higher UHC emissions can be observed for blends having higher butanol concentrations, iBut45 and nBut55. The higher fuel viscosity can be a source of larger droplet diameter and a disadvantage towards spray penetration. An increase in UHC emissions can also be observed at 14 to 18 bar IMEP for E25, iBut45 and nBut55, as compared to $\mathrm{E} 10$. $\mathrm{CH} 4$ emissions are reduced with alcohol fuels. The effect of iBut20 and nBut55 is comparable to that of E25. However, iBut45 allows a stronger reduction of $\mathrm{CH} 4$ emissions. $\mathrm{NOx}$ emissions tend to decrease for high butanol concentrations nBut55 and iBut45, and more slightly iBut20, this despite the higher fuel bore $\mathrm{O} 2$ concentration. Between 4 and 10 bar IMEP, the combustion phasing MFB50 and MFB90 (not presented here) are similar for all fuels tested, and no increase in combustion speed or advance end of combustion can be evidenced to explain the differences in NOx emissions. Study by Glaude et al. [27] indicated that butanol fuel presents a higher flame temperature than ethanol, which would typically result in higher NOx emissions. In this study, the maximum pressure variation shows lower amplitude increase for all butanol blends and could relate to the lower NOx emissions obtained. This property relates with a lower rate of temperature increase, namely for these operating points having same combustion phasing, MFB50. These characteristics would reduce NOx formation and improve NOx post-oxidation.
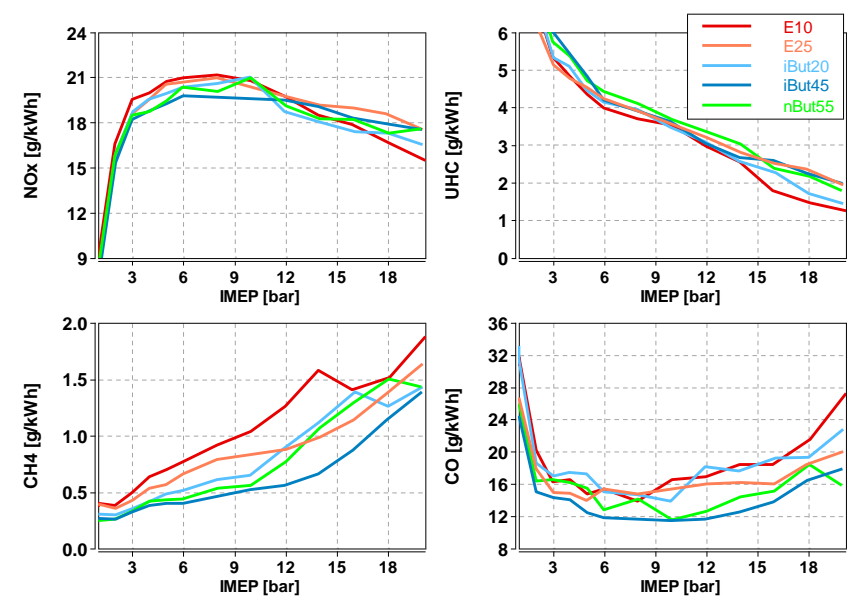

Figure 12. Emissions on NOx, HC, CO and CH4 at 2000 rpm, IMEP sweep. 


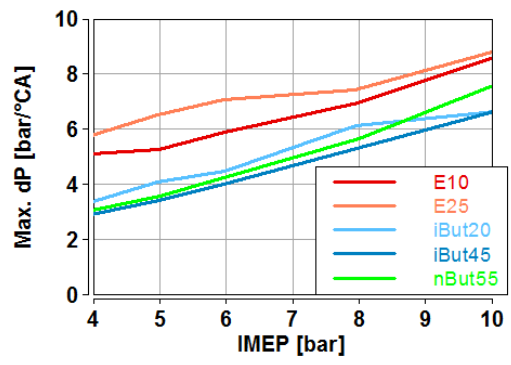

Figure 13. Maximum cylinder pressure increase at 2000 rpm, 4 to 10 bar IMEP.

At 4000 rpm, slight variations in engine-out emissions can also be observed, as illustrated in Figure 12. In the 10 to 14 bar IMEP range, the delayed combustion phasing obtained for iBut20 and nBut55 causes a reduction in the combustion temperature, and hence of NOx emissions. $\mathrm{CO}$ and $\mathrm{UHC}$ emissions are also reduced, mainly favourable to the increased mixture time. At low loads, CO and UHC emissions present slight differences, with tendencies comparable to those present at $2000 \mathrm{rpm}$. A reduction of $\mathrm{CO}$ emissions can be observed at 2 to 5 bar IMEP, for higher oxygen content fuels E25, iBut45 and nBut55; whilst iBut45 results in a slight increase of UHC emission.
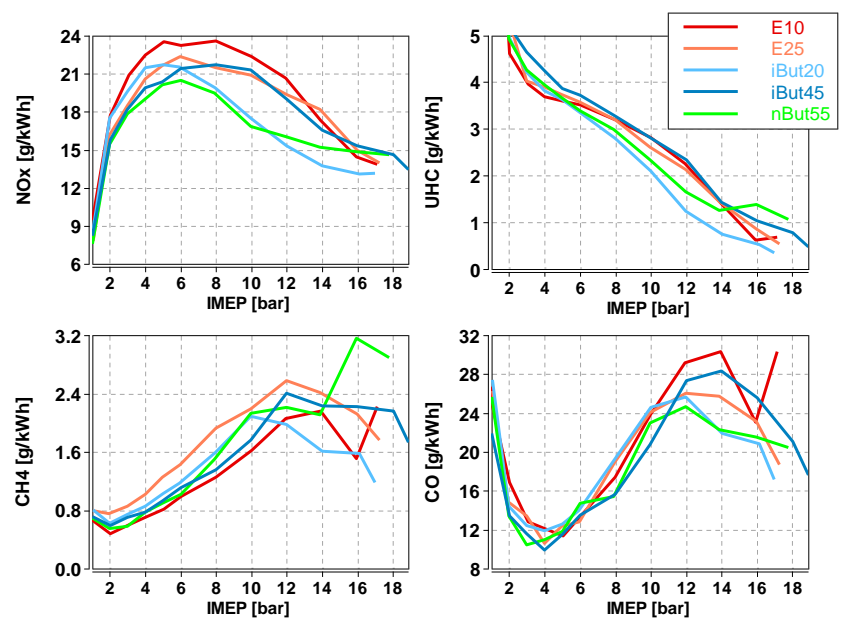

Figure 14. Emissions on NOx, HC, $\mathrm{CO}$ and $\mathrm{CH} 4$ at 4000 rpm, IMEP sweep.

Oxygenated fuels have a significant impact on the mass and number of particle emissions, and the behaviour differs between ethanol and butanol isomers. They are presented in Figure 15 and Figure 16, for 2000 and $4000 \mathrm{rpm}$ respectively. iBut20 particle emissions are compared to E10, as both fuels have a comparable oxygen concentration. At 2000 rpm, Figure 15 shows a tendency for iso-butanol fuel to reduce particle mass emissions and number, despite having similar $\mathrm{O} 2$ concentration. The results are possibly explained by iBut20's increased aromatic dilutions, as compared to E10. At high load, above 16 bar IMEP, particle mass emissions become comparable to E10. Differences in spray development, vaporisation and reaction behaviour of ethanol and butanol fuels could also lead to variations in particle emissions. At $4000 \mathrm{rpm}$, Figure 16, a similar tendency is found up to 10 bar IMEP. However, the delayed combustion phasing obtained for iBut20 reduces particle post-oxidation, probably explaining the differences obtained at higher loads. Particle size distribution is illustrated in Figure 17 for 2000 rpm, 4 and 14 bar IMEP. Comparison of iBut20 and E10 indicates that butanol at $20 \% \mathrm{vol}$ concentration favours the reduction of lower diameter particles, under $80 \mathrm{~nm}$ for low charge, and bellow $120 \mathrm{~nm}$ for higher load.

The impact of increased ethanol concentration E25 on particle emissions is variable, depending on the engine charge and speed. At $2000 \mathrm{rpm}$, Figure 15 (above), an increase of particle mass is observed in the low load range, while particle mass is reduced again at higher loads. At $4000 \mathrm{rpm}$, particle mass emissions are comparable to those obtained for reference fuel E10, Figure 16 (above), increasing slightly at lower loads and decreasing with charge. Such variable impacts of ethanol on particle emissions have also been reported in the literature $[18,28]$. They are explained by the competition that takes place between increased volatility and heat of vaporization; where both forces vary with the operating point. However, it is interesting to note how tendencies differ between iBut20 and E25; where iB20 increases aromatic dilution, at similar or higher HOV, a particle mass reduction is obtained; whilst E25 increases aromatics dilution and $\mathrm{O} 2$, at $5 \%$ higher $\mathrm{HOV}$ but results in higher particle mass. In addition, as per Table 1, butanol fuels blends present an increased viscosity which should be detrimental to the spray development. These contrasting results indicate that other effects could play a role over particle formation. Moreover, an interaction between ethanol and aromatic evaporation has been reported in the literature. According to Burke et al. [29], ethanol interacts with aromatics retarding its evaporation and creating regions of high aromatic concentration, and hence particle emissions, but no further confirmation of these properties has been published to date. Concerning the total number of particles emitted, results indicate a reduction with increased ethanol concentration for all operating points. Results of particle size distribution, Figure 17, indicate that E25 allows a reduction of mainly ultrafine particles, whilst having little effect on particles close to $100 \mathrm{~nm}$. This could explain the strong reduction in the number of total particles, whilst little impact on the particle mass is measured. Variation in particle composition and volatile ratio could also be a source of difference. The phenomena and engine characteristics that impact and explain these variations are not fully known and require further research. In the literature, the impact of ethanol on particle distribution is variable, some publications show an impact on lower diameter, and others in the larger diameter range. For example, Ratcliff et al. [12] studies particle emissions for several fuels, comparing E25 emissions against standard gasoline fuel. In this work ethanol results in the reduction of the number of particles, namely below 50 $\mathrm{nm}$. 
Contrary to tendencies found with increasing ethanol content, increasing the butanol concentration presents a strong reduction of particle mass. This variation could indicate that increasing oxygen and reducing aromatic concentrations are dominant factors over particle formation for butanol blends. Exception is found at $4000 \mathrm{rpm}$, high loads, where butanol results in a peak particle mass emission near 14 and 16 bar IMEP. Nevertheless, in this load range combustion phasing differs. If the oxygen concentration is thought to be a dominant element over particle emission reduction, the comparison of blends E25 and iBut45, at similar $\mathrm{O} 2$ concentration and "HOV fuel mass corrected", confirms that other factors also influence the particle formation and oxidation process. It is possible that as iBut45 allows a stronger reduction of aromatic concentration, it presents a reduced particle formation. On the other hand, the comparison of E25 and iBut20, didn't show a favourable emission for E25. Nevertheless, in the lower load range, where operating points count with similar combustion phasing, results indicate negative impact of ethanol against iso-butanol, on the mass of particles emitted. The butanol and ethanol blend comparison indicates that, between oxygen concentration, aromatic dilution and HOV, there is no dominant parameter controlling particle emissions. Further analysis is proposed in the following section. The differing tendencies can also be originated on their variable reactional paths.

Particle size distribution, presented in Figure 17, shows that increasing the butanol concentration at low load has a strong reduction impact on particles having a diameter above $100 \mathrm{~nm}$. At higher load, the particle number reduction takes place over the full measuring spectrum. The total particle number is generally reduced for high butanol blends, although the gain is much lower than that obtained for E25, and variable according to the operating point. At $2000 \mathrm{rpm}$ the mean total number of particles are reduced by a mean value of $43 \%, 18 \%$ and $46 \%$ for iBut 20 , iBut 45 and nBut 55, respectively. At $4000 \mathrm{rpm}$, from low load to 12 bar IMEP, the mean particle number reduction is of $18 \%, 29 \%$ and $19 \%$ for iBut 20 , iBut 45 and nBut55, respectively. However, differences between operating points are present. At $2000 \mathrm{rpm}$ and loads up to 6 bar IMEP, increasing the iso-butanol concentration results in an increased number of total particles as compare to iBut20. iBut45 particle emissions are close to fuel E10. However, for other operating points, the tendency is a reduction of the total number of particles. This could be explained by a competition between the favourable increased fuel oxygen concentration and lower aromatics concentration, against a higher heat of vaporization. This last parameter being possibly more significant at lower load and surface temperature. nBut55 blend shows the strongest reduction on both particle mass and particle number, possibly due to the strongest oxygen concentration and aromatic reduction.
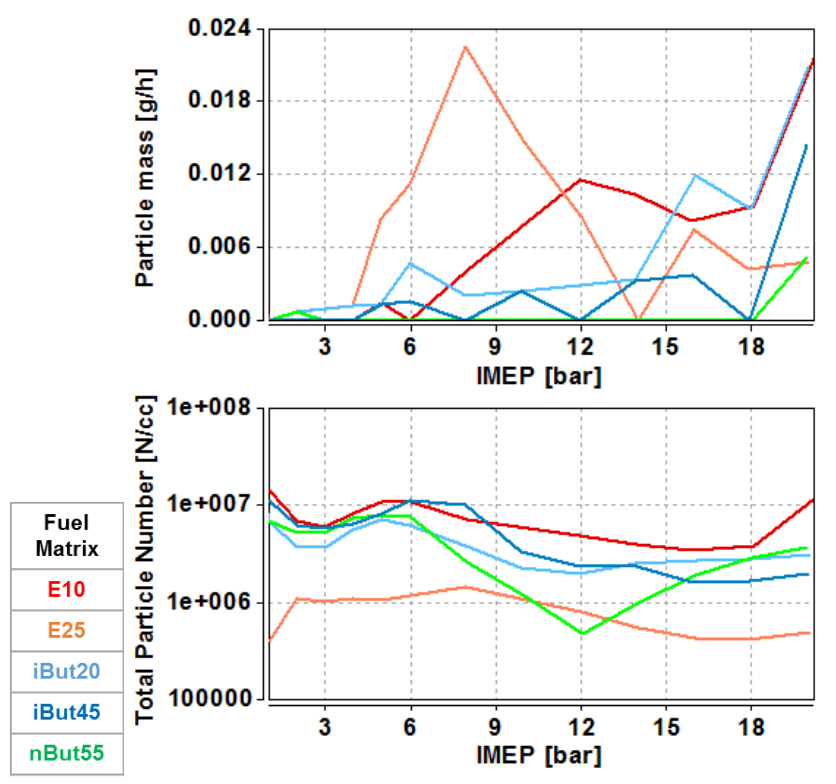

Figure 15. Particle mass and number at 2000 rpm, IMEP sweep.
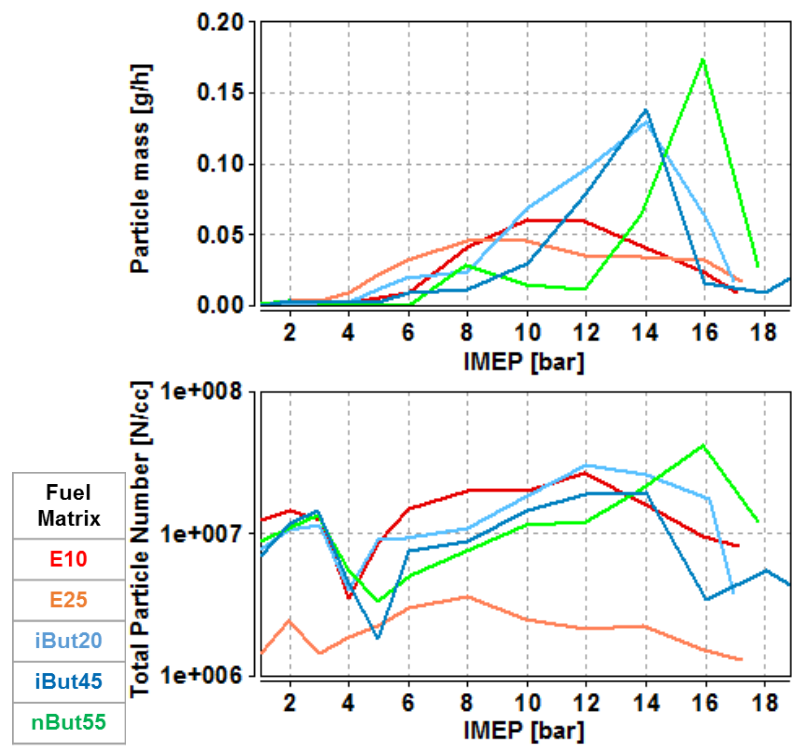

Figure 16. Particle mass and number at 4000 rpm, IMEP sweep.

The results highlight an overall positive effect of butanol blending on particle mass emissions, mainly reducing particles of larger size, and thus influencing simultaneously particle mass and number emissions. If this and other studies have shown that ethanol can have a negative or limited effect on particle mass under certain operating conditions, butanol shows an overall stronger reduction potential. However, the total number of particles, and mainly ultra-fine particles are not reduced with butanol blending. It underlines the importance of understanding the phenomena and engine parameters affecting the total number of ultra-small and small particle number, not fully known to date. Studies in this area could help understanding the different impacts of ethanol and butanol over particle size distribution. 


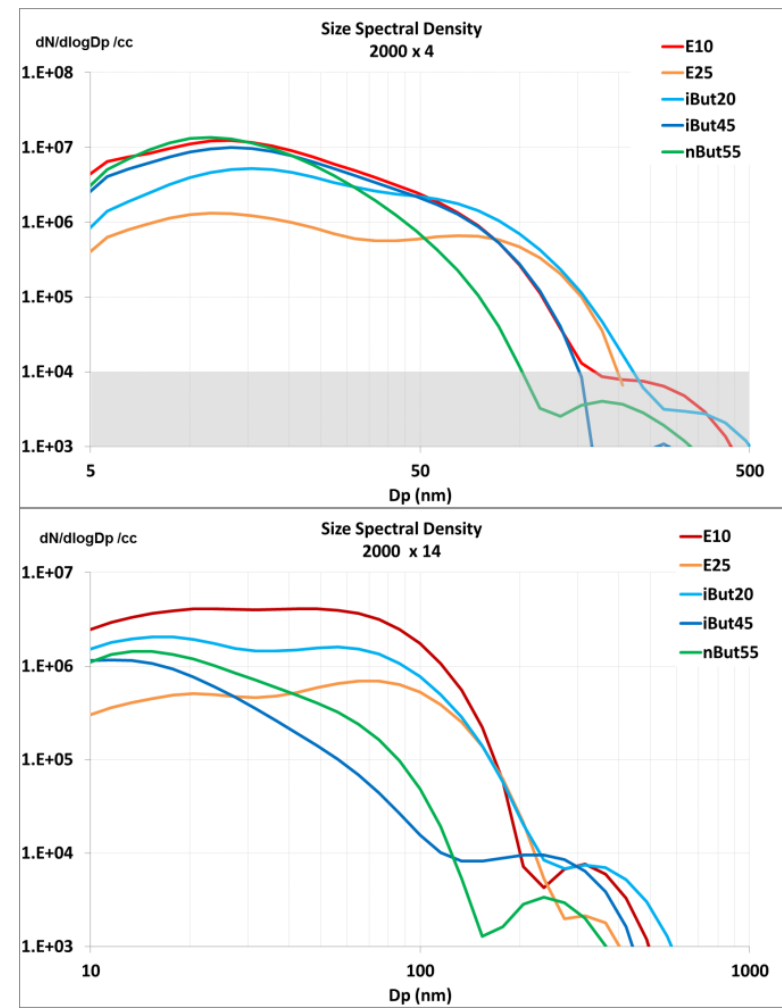

Figure 17. Particle diameter distribution at 2000 rpm, at 4 and 14 IMEP.

These results highlight that if butanol allows a reduction of particle number, the effect is dependent on the blend and operating point with no linear tendency obtained with concentration or charge variation: lower iso-butanol concentration favours lower particle emissions at low operating charge points, but increasing butanol concentration has no impact on particle number in this operating area, whilst being favourable at cold operation and higher loads.

\section{COLD OPERATION}

Cold operation tests were carried out at $2000 \mathrm{rpm}$, and 2 bar IMEP under stabilized conditions, at $30^{\circ} \mathrm{C}$ oil and coolant temperature. To simplify variables for analysis purpose, the point was operated using a single injection, and combustion was set at constant timing. All fuel blends presented similar stability and combustion duration characteristics.

Cold operation has a significant effect over UHC and particle emissions. Figure 18 illustrates the UHC factor increase obtained under cold operation, with respect to $90^{\circ} \mathrm{C}$. For reference fuel $\mathrm{E} 10$, reducing the engine temperature to $50^{\circ} \mathrm{C}$, increases the $\mathrm{UHC}$ emission by a factor of 1.4 , and a further temperature reduction to $30^{\circ} \mathrm{C}$ increases emissions by a factor of 1.8. Similar tendency is found for fuel E25, where low temperature $30^{\circ} \mathrm{C}$ operation results in an increased factor of 1.7. Results obtained for butanol blends indicate a reduced impact of engine temperature over $\mathrm{UHC}$ emissions. For fuel blend iBut20, UHC increase by a factor of 1.2 and 1.5 , at 50 and $30^{\circ} \mathrm{C}$, respectively. At increased iso-butanol concentration, iBut45, UHC emission increase, and tendency is close to that of E25. nBut55 presents same UHC emissions at $50^{\circ} \mathrm{C}$ as reference fuel $\mathrm{E} 10$, but increased at lower temperature of $30^{\circ} \mathrm{C}$. Compared to ethanol fuel blends $\mathrm{E} 10$ and $\mathrm{E} 25$, under cold operation, a positive effect of butanol blends on UHC emissions can be obtained up to a concentration of $45 \%$ vol of i-butanol. For nBut55, the effect is positive at temperature of $50{ }^{\circ} \mathrm{C}$. Iso-butanol attenuates the UHC emissions increase as temperature is reduced, and best compromise is obtained for IBut20.

iBut20 viscosity and heat of vaporization (Figure 1) are comparable to E10 blend and, together with the high oxygen concentration, probably count for the improved UHC emissions. High butanol and ethanol blending, iBut45, nBut55 and E25, increase viscosity, density and/or enthalpy of vaporization; properties that will have a negative effect on fuel spray and UHC emissions [30]. The results underline the importance and impact of oxygenates over spray and mixture, combustion and oxidation, affecting UHC emissions.

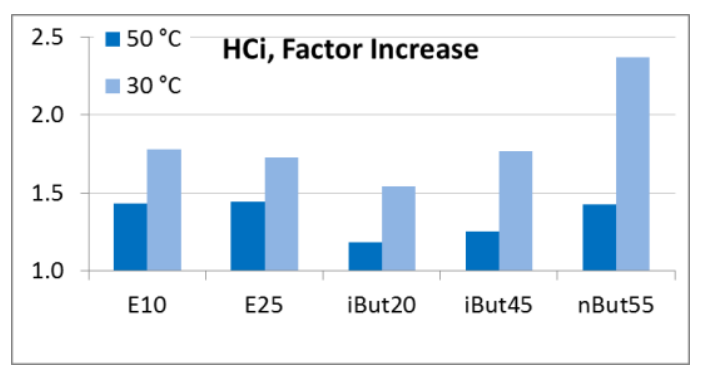

Figure 18. Indicated HC emissions factor increase at reduced engine temperature, compared to warm operation $90^{\circ} \mathrm{C}$. Operating point 2000 rpm, 4 bar IMEP.

Particle mass emissions under cold operation are illustrated in Figure 19. Increased ethanol concentration E25 reduces particle mass emissions by $44 \%$ at $50{ }^{\circ} \mathrm{C}$ and $11 \%$ at $30^{\circ} \mathrm{C}$, with respect to reference $\mathrm{E} 10$. For Butanol fuel blends, the adverse impact of low engine temperature on particle emissions is strongly reduced, moreover as the butanol concentration is increased. At comparable blending ratio, iBut20 allows a stronger particle emission reduction than that of ethanol. This effect is intensified at $30^{\circ} \mathrm{C}$. It is probable that the lower enthalpy of vaporization of iBut20 compared to E25 (Figure 1) is favouring this tendency. At higher butanol concentration, despite the fact that the enthalpy of vaporization increases, the higher oxygen concentration and reduced aromatics could be responsible for the low particle emissions. However, elements available do not allow to determine if other phenomenon explain the stronger particle reduction obtained with butanol with respect to ethanol.

The number of particle emitted are illustrated in Figure 20. The graphs present the total number of particles, and differentiation between nucleation (approximately bellow $23 \mathrm{~nm}$ ) and accumulation particles (approximately above $23 \mathrm{~nm}$ ) is included. These regions are calculated by DMS500 software by means of log-normal distribution analysis. Results indicate that for ethanol blends, a reduction of the operating 
temperature from 90 to $50^{\circ} \mathrm{C}$ and $30{ }^{\circ} \mathrm{C}$, induces a particle number increase. The tendency is stronger for E10 and reduced with higher ethanol content E25. However, butanol blends results do not reveal a negative impact of low temperature operation on particle emission. In fact, a reduction of the total number of particles has been observed for iBut20, iBut45 and nBut55. The reduction is strongest at $50{ }^{\circ} \mathrm{C}$, whilst at lower temperature of $30^{\circ} \mathrm{C}$ the particle emissions are maintained comparable or lower than at $90^{\circ} \mathrm{C}$. Analysis of particle size distribution shows that the impact is mainly obtained for higher particle diameter, i.e. above $23 \mathrm{~nm}$. Larger particles are strongly reduced for butanol fuels iBut45 and nBut55, and at $50{ }^{\circ} \mathrm{C}$ become lower than E25. Nevertheless, total particles emissions ( 5 to $1000 \mathrm{~nm}$ ) obtained with butanol fuel blends remain higher than those of E25. Fuel distillation data could help explain tendencies.

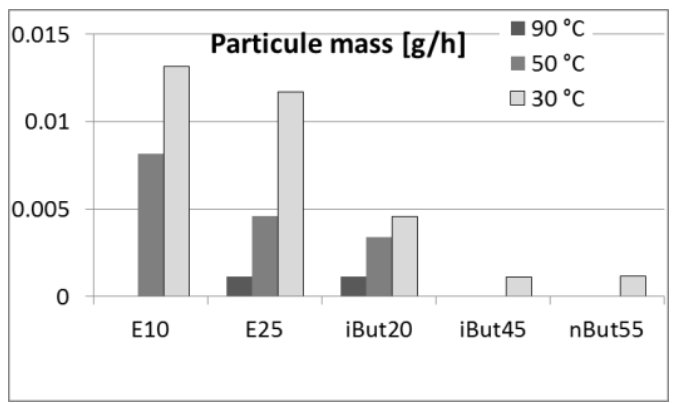

Figure 19. Particle mass emitted at 2000 rpm, 4 bar IMEP, cold operation.

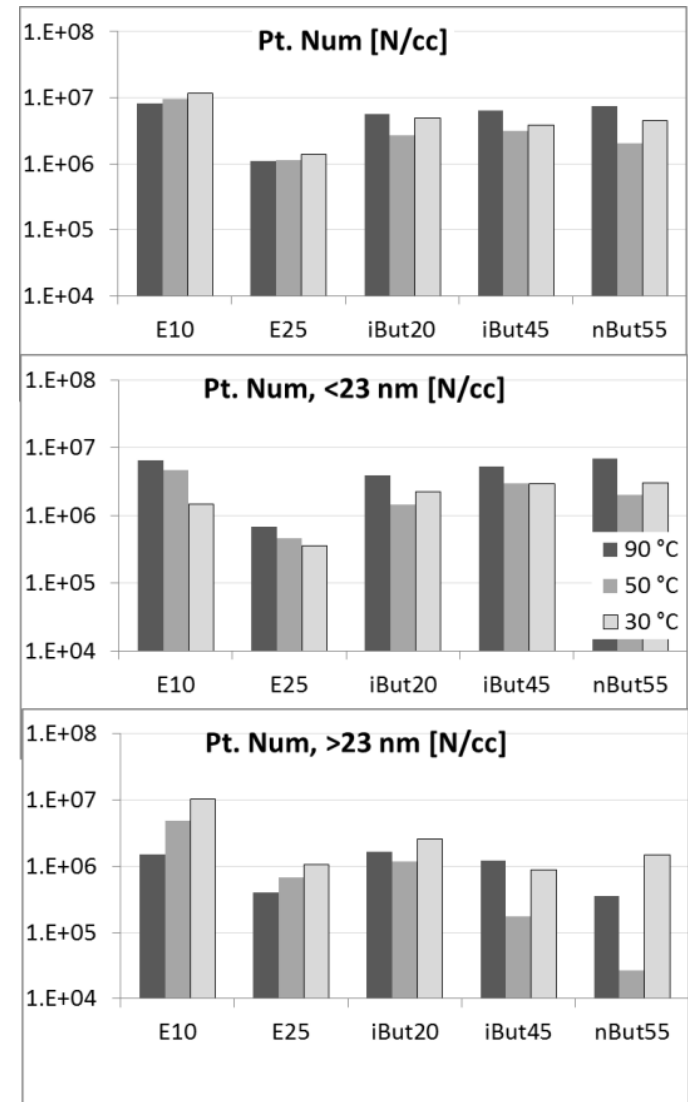

Figure 20. Number of particles emitted at 2000 rpm, 4 bar IMEP, in the full diameter range (above), small diameter range $<23 \mathrm{~nm}$ (middle), and higher diameter range (low).

\section{FUEL COMPOSITION EFFECT ON PARTICLE EMISSIONS AND PARTICLE MATTER INDICES}

Several studies have quantified the impact of fuel blends over the particles emitted through the definition of Particle Matter (PM) Indices. Amongst the most renowned publications is the works by Aikawa et al. [31]. These correlations have been confirmed for several commercial and non-certified gasoline blends, and for different specific compounds variations [32] on the basis of driving cycle emissions. More recently, Ben Amara et al. [15] have synthetized the different PM indices found in the literature, and their correlations to specific fuel properties. Of these, PMIParticulate Matter Index, OESI ${ }^{*}$-Oxygen Extended Sooting Index, and SP*- Smoke Point Petroleum Institute Correlation, have proven high correlation factors with regards to driving cycle particle emissions. As oxygenated fuels have become of increasing interest, the study of PM indices has extended on to their application and blends. However, the use of conventional PM indices on oxygenated fuel blends has proven the correlations weaker, or of having relations that differ from non-oxygenated gasolines [16, 33, 34]. As a consequence, some studies have aimed at defining new correlations that can be adapted to oxygenated fuel blends [35]. For example, Ratcliff et al. [12] showed good correlation over operating point $2000 \mathrm{rpm}$, and 13 bar IMEP, for $16 \%$ iso-butanol. According to their results, this operating point has the particularity of presenting an increase of the number and mass of particles emitted, and does not correspond to the overall tendency found in the results presented here. Some reasons that could explain the divergences are the differences in injection system and injection pressure used (wall guided WG and low pressure, against spray guided $S G$ and high pressure), that increase piston and liner liquid fuel film, and thus the effect of the fuels' evaporation characteristics over particle formation.

With the aim of introducing elements of comprehension on the effect of butanol blends over PM indices, and their correlation to particle number emissions, several indices have been calculated for the butanol and ethanol blends studied.

\section{$\underline{\text { Particle Matter Indices }}$}

The PM indices analysed are Particle Matter Index $\mathrm{PMI}$, Oxygen Extended Sooting Index OESI ${ }^{*}$, and Smoke Point SP*, as correlated by the Petroleum Institute. They are described in Equation 2, Equation 3 , and Equation 4, respectively.

$$
P M I=\sum_{i=1}^{n}\left(\frac{D B E_{i}+1}{V P_{443 K}} W t_{i}\right)
$$

Equation 2

$$
O E S I^{*}=a^{\prime} \frac{M w_{\text {fuel }}}{S P^{*}}\left(\frac{W t_{C}}{12.011}+\frac{W t_{H}}{4 \times 1.008}-\frac{W t_{O}}{2 \times 15.999}\right)+b^{\prime}
$$

Equation 3 
Where:

- $\mathrm{VP}$ is the absolute Vapor Pressure at $443 \mathrm{~K}$;

- Wt are the weight percentage, where $\mathrm{C}, \mathrm{H}$ and $\mathrm{O}$ stand for carbon, hydrogen and oxygen, respectively;

- Mw is the molecular weight of the blend;

- $a$ and b are constants valid for all experimental setups; and

- DBE is the Double Bound Equivalent, calculated as a function of the number of carbon atoms $\mathrm{C}$, hydrogen atoms $\mathrm{H}$ and nitrogen atoms $\mathrm{N}$, as following the relationship:

$$
D B E=(2 * C+2 * H+N) / 2
$$

- and, SP* is the smoke point Petroleum Institute correlation, from the mass fraction content of Paraffins P, Naphthenes N, and Aromatics $\mathrm{A}$,

$$
S P^{*}=1.650 X-0.0112 X^{2}-8.7
$$

Equation 4

Having

$$
X=100 /(0.0061 P+0.03392 N+0.13518 A)
$$

According to analysis presented by Ben Amara et al. [15], PMI has a good representation over aromatic variations. PMI calculated for butanol and ethanol blends are presented in Figure 21 against the aromatic concentration. It shows that the aromatic dilution has a mayor effect on the PMI and no differentiation is made between butanol isomers and ethanol. This is specially the case for this fuel variation having the same base gasoline fuel and no modification of the aromatic compounds, other than dilution. Another index that it is known to correlate to the aromatic concentrations is $100 /$ SP $^{\star}$ [15], and it is presented in Figure 22, confirming the tendency.

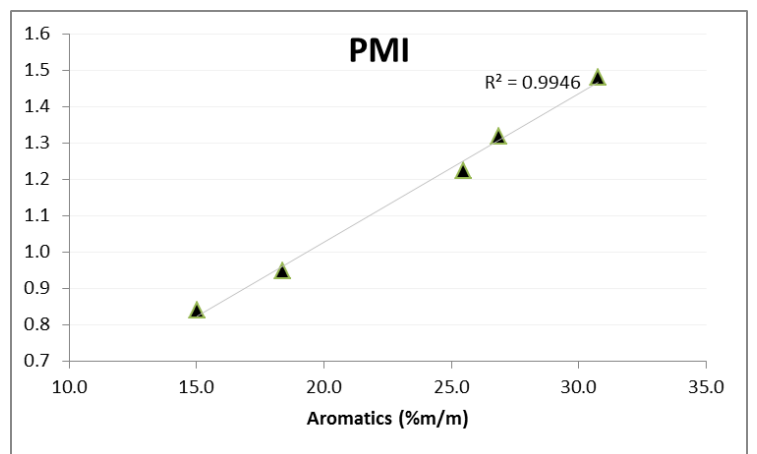

Figure 21. PMI against aromatic concentration $(\% \mathrm{~m} / \mathrm{m})$.

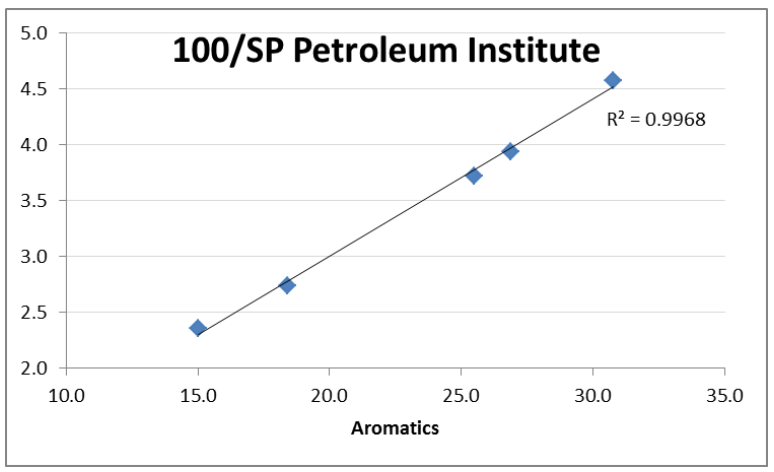

Figure 22. 100/SP* (Petroleum Institute) against aromatic content $(\% \mathrm{~m} / \mathrm{m})$.

OESI $^{*}$ values are presented in Figure 23. Previous works have demonstrated that this index follows close trends with other indices (e.g. SP* and TSI Threshold Sooting index-not presented in this work), but has the advantage of including experimental factor Smoke Point, SP, as well as the oxygen content for oxygenated blends [15]. This characteristic could differentiate ethanol and butanol blends, as they induce variable oxygen concentration at constant aromatic dilution. Calculated $\mathrm{OESI}^{*}$ value is plotted against aromatic and oxygen concentration $(\% \mathrm{~m} / \mathrm{m})$ in Figure 23. It shows a strong correlation to oxygen content, whilst correlation to the aromatic content is somewhat weaker.

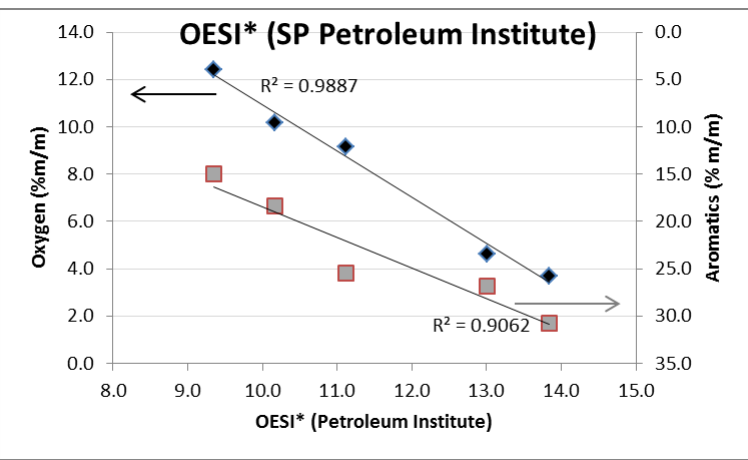

Figure 23. Oxygen and aromatic concentration $(\% \mathrm{~m} / \mathrm{m})$ against OESI*

\section{Particle emissions with respect to Particle Matter $\underline{\text { Indices }}$}

The mean ratio of the particle emissions of each fuel, with respect to the reference E10, has been plotted against the PM indices PMI and $\mathrm{OESI}^{*}$. They are represented in Figure 24. The number of particle has been calculated on the basis of warm engine operating conditions (red in figure) and cold operation (at 50 and $30^{\circ} \mathrm{C}$, blue in the figure). The comparison is based on single cylinder engine stabilised operation, and differs from typical representations made on vehicle cycle emissions tests (e.g. Worldwide harmonized Light vehicles Test Cycles WLTC, or the New European Driving Cycle NEDC). The aim is to compare emission tendencies with respect to fuel particle matter indices, for butanol and ethanol fuels. 
Results on the basis of PMI (Figure 24, above) show that, under stabilized operating conditions, butanol blends present similar tendencies under warm and cold operation, where a reduction of the number of particle takes place for lower PMI fuels. Moreover, iso-butanol and $\mathrm{n}$-butanol blends present similar trends. The particle reduction, with respect to E10, is stronger under cold operation. However, higher ethanol concentration E25 has little impact on PMI whilst a stronger particle number reduction was obtained. Moreover, no clear relation can be found between butanol and ethanol blends as based on index PMI. Representation of particle emissions over OESI $^{*}$ (Figure 24, bellow) shows that, for each alcohol group, a reduction of the $\mathrm{OESI}^{*}$ value is representative of a reduction of particle emissions. The trend line of $n$-butanol blend is close to that of iso-butanol (represented in the figure for guidance). However, ethanol and butanol blends' particulate reduction correlates differently to $\mathrm{OESI}^{*}$. Ethanol concentration increase from 10 to $25 \%$ vol has a stronger impact than butanol isomers.

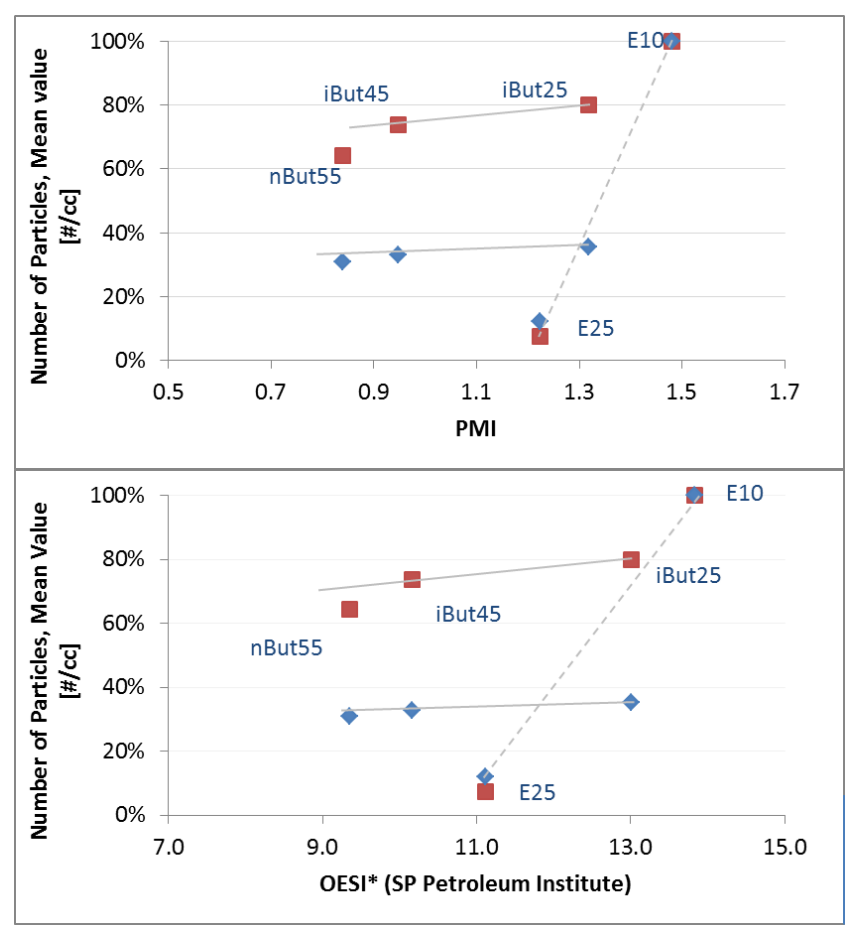

Figure 24. Mean ratio of particle emissions, with respect to reference fuel E10, represented over PMI (above) and OESI* (below). Mean warm operation charge sweep at 2000 and $4000 \mathrm{rpm}$ (red); and cold operation at $2000 \mathrm{rpm}$, 4 bar IMEP (bleu).

The particle reduction ratio of butanol blends with respect to ethanol blends, and their different correlation to particle matter indices $\mathrm{OESI}^{\star}, \mathrm{PMI}$ and $100 /$ SP $^{*}$, is an indication that, if vapour pressure, aromatic and oxygen concentration are significant parameters over particle reduction, they alone do not respond to the impact of these alcohols on particle emissions. Possible competitive effects could take place reducing or enhance particle formation and oxidation; the conditions for these being more or less pronounced according to operating points. The variable tendencies found for the butanol blends, in the low-load and mid-load ranges, are an example of this (Figure 15 and Figure 16). That is, increasing the oxygen and dilution concentrations of iBut 45 against iBut20, had no- to negative effect- between 2 and 5 bar IMEP. However an opposite tendency was found at higher loads. Moreover, such a trend was not distinguished for higher ethanol blend E25. These differentiating behaviour of butanol and ethanol blends could hamper the application of PM indices to oxygenated fuels. It is possible that one of the underlying phenomenon is the higher heat of vaporization of iBut45 and nBut55, characteristic that will possibly become more relevant under lower engine temperature, i.e. at low load and speed, and it is known to hinder fuel vaporization, and hence increase particle formation. It is also possible that the effect of increased oxygenated over the reduction of local rich areas will become dominant namely for operating points having longer injection time, at higher load. Moreover, PM indices do not represent changes in fuels viscosity that impact spray development and droplet distribution. Another interesting comparison between ethanol and butanol fuel blend is the particle size distribution. The number of particle to PM indices analysis is based on measurement that account for the 5 to $1000 \mathrm{~nm}$ range. Nevertheless, ethanol and butanol have a differentiated impact on the nucleation and agglomeration particle type. Ethanol fuel blend shows a stronger reduction on the lower diameter particles, namely in section between 5 to $23 \mathrm{~nm}$; whilst butanol fuels impact was found mainly in the larger diameter particle, above $23 \mathrm{~nm}$ (Figure 17). These differences will have a significant effect on PM index correlations, as measuring range is varied. It is therefore important to understand the fuel parameters than influence the smaller and larger particle emissions, namely as extension of regulated minimum particle size is expected to be reduced, from limit of 23 to $10 \mathrm{~nm}$.

\section{ALDEHYDE EMISSIONS}

The use of oxygenated fuels also affects unregulated carbonyl emissions [13, 18, 36]. Carbonyl compounds are known to have an impact on human health and ozone formation. They are mainly looked upon on Diesel compression ignition combustion, as gasoline carbonyl emissions are typically lower in concentration [31]. However, the literature confirms an increase of oxygenated emissions when alcohols are incorporated into gasoline, as has been stated by Storey et al. [18] and Karavalakis et al. [13]. These studies were based on butanol concentrations up to $48 \%$ and $32 \%$. No comparison is made with n-Butanol. Results obtained by Karavalakis et al. indicate a strong variability dependent on the engine configuration, i.e. spray and wall guided injection.

Studies [37, 38] have listed most aldehydes as having cancerogenic risk, or of being irritants, genotoxic and cytotoxic; of which formaldehyde, acetaldehyde, and acrolein are known to have the strongest effect on health. Some carbonyl compounds are also known for having high incremental reactivity for ozone formation 
[39]. The Maximum Incremental Reactivity (MIR) quantifies the potential of such species to contribute to the ozone production. The overall ozone formation potential of exhaust gases is calculated using Equation 5, where SC is the specific carbonyl concentration for each compound. The aldehydes having highest MIR values are formaldehyde, crotonaldehyde, acroline, propionaldehyde and acethaldehyde; of which formaldehyde and acetaldehyde are the highest carbonyl compounds in gasoline exhaust gas emissions [34]. The factor increase or reduction of OP, with respect to reference fuel E10, will be analysed for the fuel blend matrix [40].

$$
O P=\sum S C \times M I R
$$

Equation 5

For the analysis of aldehyde emissions, exhaust gases were diluted and collected using cartridges containing 2,4-dinitrophenylhydrazine (DNPH). Emissions results presented have been corrected taking into account the dilution ratio. Sampling duration is set to $10 \mathrm{~min}$, at a specified flow. These factors have been set to ensure that the concentrations of carbonyl compounds are adequate for the chromatographic analyser.

Aldehydes analysis has been carried out for an operating point at low load, $2000 \mathrm{rpm}, 4$ bar IMEP, and it's sensibility to EGR dilution. Additionally, high load point $4000 \mathrm{rpm}$ and 16 bar IMEP, and a cold operation conditions at $2000 \mathrm{rpm}$ and 4 bar IMEP, have also been analysed. Hereafter, results will be presented for these operating points, in the listed order. Detailed aldehyde emissions are represented in Figure 25. For this comparison, the EGR dilution has little impact on the characteristics of each fuel blend and has been left out for simplicity. Results show that increasing ethanol blend from 10 to $25 \%$ vol has little impact on the total concentration of aldehydes, under warm operation. However, an increase is detected under cold operation. In fact, at low load ethanol contributes to the reduction of formaldehyde emissions, whilst acetaldehyde increases. This effect is enhanced under low temperatures. At high load, main emitted compounds, formaldehyde and acetaldehyde increase. As these $\mathrm{C} 1$ and $\mathrm{C} 2$ aldehydes have a high MIR value, the total potential ozone formation, represented in Figure 26, tends to reduce at low load (0.7), but increase at high load and under cold operation (1.2 and 1.3 respectively). Blend of $20 \% \mathrm{vol}$ iso-butanol results in a reduction of the total aldehyde emissions, regardless of the operating point or condition. Reduction of total emissions (Figure 26) are of 6, 23, 24 and $12 \%$, at speeds and loads (rpm x bar IMEP): 2000x4, 2000x4 EGR, $4000 \times 16$ and $2000 \times 4$ cold, respectively. However, specific compounds present different tendencies. Formaldehyde and acethaldehyde are reduced; whilst longer chain aldehydes (C3 and C4), acetone, propionaldehyde and butyraldehyde, increase. Similar tendencies have also been found for low isoButanol concentrations by Storey et al. [18] and Karavalakis et al. [13]. The impact on formaldehyde results in a reduced ozone formation factor, of 0.7 to 0.8 depending on the operating point. Unlike E25, the total emissions do not increase at low engine temperature. If iso-Butanol pyrolysis reactions result in the formation of acethaldehyde, the pathway is not as strong as that of Ethanol [13]. In fact, iso-butanol reaction pathways [9] for propionaldehyde and acethaldehyde compete against each other, being propionaldehyde concentration highest.
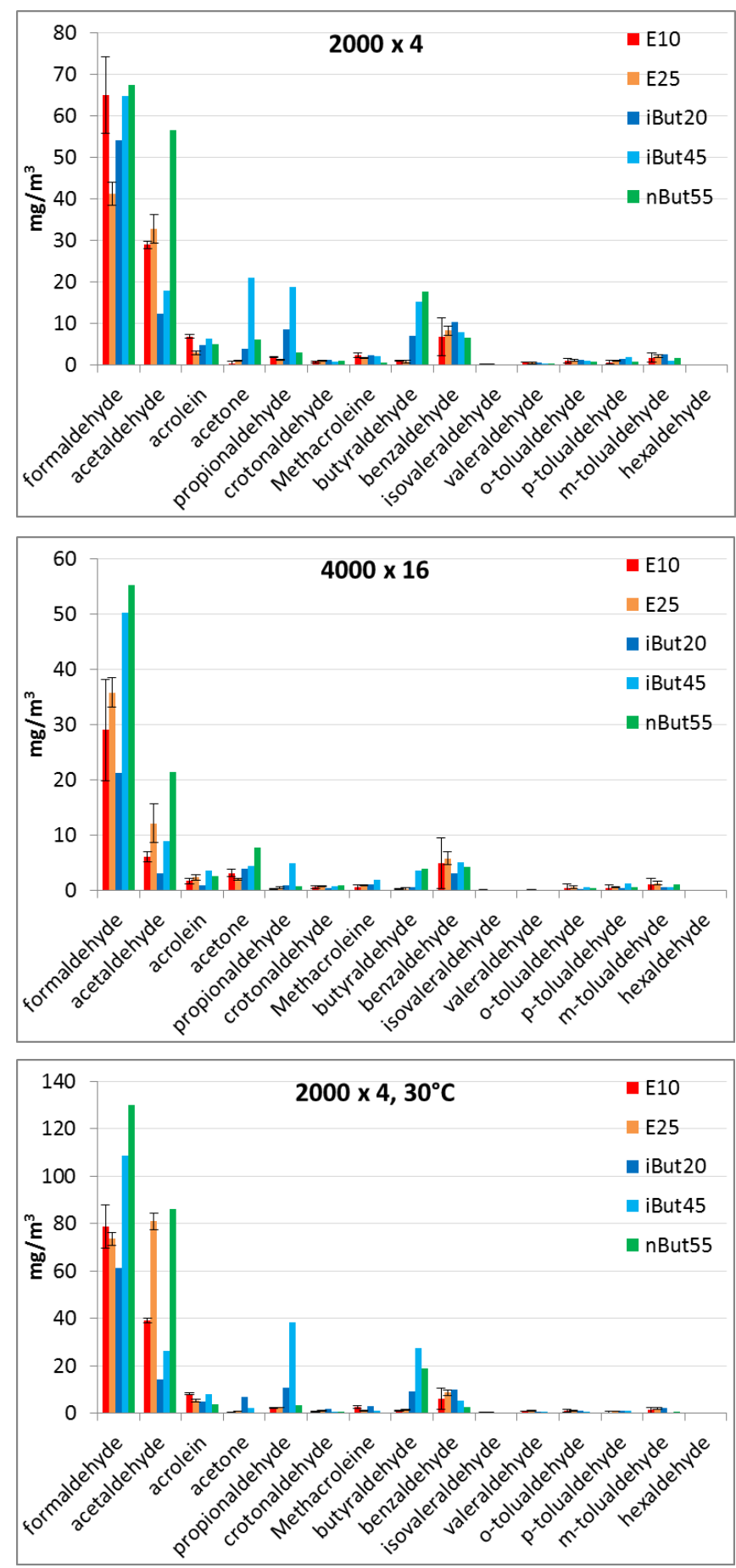

Figure 25. Carbonyl emissions for different fuels blends E10, E25, isoButanol20, isoButanol45, nButanol55. Operating conditions are represented in a) $2000 \mathrm{rpm}, 4$ bar IMEP; b) $4000 \mathrm{rpm}, 16 \mathrm{bar}$ IMEP; c) $2000 \mathrm{rpm}, 4$ bar IMEP under cold cooling fluid, $30^{\circ} \mathrm{C}$. 


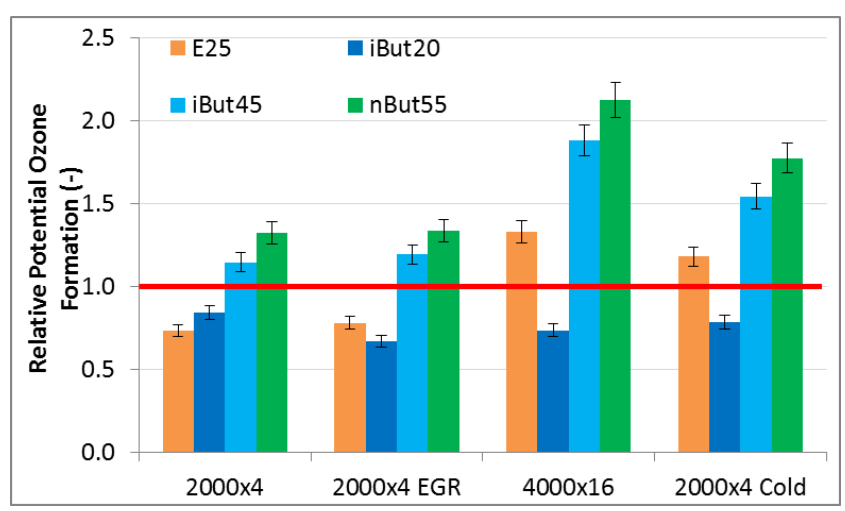

Figure 26. Relative Potential Ozone Formation for different fuels blends E10, E25, iBut20, iBut45, nBut55. Operating conditions represented 2000 rpm, 4 bar IMEP with and with-out EGR; $4000 \mathrm{rpm}, 16$ bar IMEP; and 2000 rpm, 4 bar IMEP under cold cooling fluid, $30^{\circ} \mathrm{C}$.

As iso-butanol concentration increases to $45 \% \mathrm{vol}$, formaldehyde emissions will exceed those of the reference fuel under high load and cold operation conditions. As a consequence the impact on total carbonyl emissions is that of an increase of $35 \%$, $18 \%, 76 \%$ and $55 \%$ for the operating points. The ozone formation potential is hence increased by a factor of 1.1, 1.2, 1.9 and 1.5; being highest under cold operation and high load. iBut45 emissions are also stronger than those of E25 fuel blend. Results for n-Butanol, $55 \%$ vol, present a higher increase in total aldehyde emissions (Figure 26); calculated at $42 \%$, $26 \%, 102 \%$ and $73 \%$ for the operating points. The increase takes place in long and short chain aldehydes; where formaldehyde, acetaldehyde, and butyraldehyde are the main compounds. Ozone factors are consequently increased, factors being 1.3, $1.3,2.1$ and 1.8 for the individual operating points. It has been reported in works by Yasunaga et al. [36] that, unlike iso-butanol reaction pathways, acethaldehyde is one of the major pyrolysis products of $n$-butanol.

The results confirm that oxygenated fuels have a negative influence over engine-out carbonyl emissions and ozone formation potential, but for butanol isomers, the aggravation is only obtained at high concentrations of $45 \% \mathrm{vol}$ iso-butanol and $55 \%$ vol n-butanol. Results indicate that iso-butanol enhances primarily the production of formaldehyde, propionaldehyde and butyraldehyde. $\mathrm{N}$-butanol enhances mainly formaldehyde and acetaldehyde emissions.

\section{CONCLUSION}

Study of performance and emissions has been carried out on several butanol and ethanol blends. Blends have been defined on a basis of target RON (RON95 and RON101), to quantify potential of butanol fuels (iso-butanol and $n$-butanol) over fuel consumption, and emissions, as compared to ethanol blends. Butanol blends have shown good performance and emissions levels. Under non-knocking operation, combustion efficiency is only slightly reduced for high butanol concentrations (iBut45 and nBut55). Consequently, variation of fuel consumption is ruled by the reduced energy density of the oxygenated fuels. Fuel consumption of iBut20 is close to reference fuel $\mathrm{E} 10$, while blends iBut45 and nBut55 present similar fuel consumption to E25.

Under knocking conditions, at low engine speed $2000 \mathrm{rpm}, \mathrm{RON}$ and Sensitivity remain the most relevant fuel properties affecting combustion efficiency and fuel consumption, and Butanol isomers' knocking behaviour is strongly correlated to that of ethanol blends. At $4000 \mathrm{rpm}$, comparaison between butanol and ethanol blends is weak, and no strong correlation is found between the blends and their fuel octane index properties (RON and sensitivity) or heat of vaporisation.

Engine-out emissions indicate similar results, where a reduction in $\mathrm{CO}$, NOx and particle mass can be highlighted for butanol isomers. UHC emissions present slight variations, and indicate an opposing effect of reduced $\mathrm{C} / \mathrm{H}$ ratio, and viscosity.

Particle number emissions show variable tendencies, depending on the butanol isomer, its concentration, and the engine operating point. Thus no monotonic tendency is found as a function of oxygen or aromatic concentration, suggesting that other interactions take place, and differ from ethanol blends. In general, butanol allows a reduction of larger particles, whilst ethanol reduces smaller diameter particles. Moreover, results underline difficulties comparing these oxygenate blends based on Particle Matter Indices.

Carbonyl emissions have also been studied for the proposed butanol blends. Results have indicated that increasing aldehyde emissions can be obtained. However, impact over the variable compounds is dependent on the butanol isomer. Iso-butanol enhances primarily the production of formaldehyde, propionaldehyde and butyraldehyde; and $\mathrm{N}$-butanol enhances mainly formaldehyde and acetaldehyde emissions. The impact on potential ozone formation has been quantified, it increases for high butanol content iBut45 and nBut55; whilst iBut20 has no negative impact on carbonyl emissions as compared to E10 fuel.

\section{ACKNOWLEDGMENTS}

This project has received funding from the European Union's Horizon 2020 research and innovation programme under grant agreement No 640720 .

The authors would like to acknowledge Dr. A. Ben Amara and Dr. T. Tahtouh for their contribution on calculation of Particle Matter indices, and the interesting discussions.

Special thanks to A. Alindre and M. De Sousa for the technical support and engines testing. 


\section{REFERENCES}

[1] Rui Miao, Xufeng Liu, Elias Englund, Pia Lindberg et al., "Isobutanol production in Synechocystis PCC 6803 using heterologous and endogenous alcohol dehydrogenases,"

[2] Rui Miao, Hao Xie, Felix M. Ho, and Peter Lindblad, "Protein engineering of a-ketoisovalerate decarboxylase for improved isobutanol production in Synechocystis PCC 6803,"

[3] Zuodong Qina, Gregory J. Dunsa, Ting Pana, Fengxue Xin, "Consolidated processing of biobutanol production from food wastes by solventogenic<ce:italic>Clostridium</ce:italic>sp. strain HN4," Bioresource Technology 264 (2018), September 4, 2018.

[4] Ánxela Fernández-Naveira, María C Veiga, and Christian Kennes, "H-B-E (hexanol-butanol-ethanol) fermentation for the production of higher alcohols from syngas/waste gas," J Chem Technol Biotechnol 92:712-731, 2017.

[5] Regalbuto, C., Pennisi, M., Wigg, B., and Kyritsis, D., "Experimental Investigation of Butanol Isomer Combustion in Spark Ignition Engines," SAE Int. $J$. Engines 2012-01-1271, doi:10.4271/2012-01-1271.

[6] Sarathy, S.M., Oßwald, P., Hansen, N., and Kohse-Höinghaus, K., "Alcohol combustion chemistry," Progress in Energy and Combustion Science 44:40-102, 2014, doi:10.1016/i.pecs.2014.04.003.

[7] Kalamaras, C., Shaik, K., Kalghatgi, G., Babiker, $\mathrm{H}$. et al., "SuperButol ${ }^{\mathrm{TM}}-\mathrm{A}$ novel high-octane gasoline blending component," Fuel 195:165-173, 2017, doi:10.1016/i.fuel.2017.01.062

[8] Splitter, D.A. and Szybist, J.P., "Experimental Investigation of Spark-Ignited Combustion with High-Octane Biofuels and EGR. 1. Engine Load Range and Downsize Downspeed Opportunity," Energy Fuels 28(2):1418-1431, 2014, doi:10.1021/ef401574p.

[9] Zhang, Z., Wang, T., Jia, M., Wei, Q. et al., "Combustion and particle number emissions of a direct injection spark ignition engine operating on ethanol/gasoline and $\mathrm{n}$-butanol/gasoline blends with exhaust gas recirculation," Fuel 130:177-188, 2014, doi:10.1016/j.fuel.2014.04.052.

[10] Karavalakis, G., Short, D., Vu, D., Villela, M. et al., "Evaluating the regulated emissions, air toxics, ultrafine particles, and black carbon from SI-PFI and SI-DI vehicles operating on different ethanol and iso-butanol blends," Fuel 128:410-421, 2014, doi:10.1016/j.fuel.2014.03.016

[11] Lattimore, T., Herreros, J.M., Xu, H., and Shuai, S., "Investigation of compression ratio and fuel effect on combustion and PM emissions in a DISI engine," Fuel 169:68-78, 2016, doi:10.1016/i.fuel.2015.10.044.
[12] Ratcliff, M.A., Burton, J., Sindler, P., Christensen, E. et al., "Knock Resistance and Fine Particle Emissions for Several Biomass-Derived Oxygenates in a Direct-Injection Spark-Ignition Engine," SAE Int. J. Fuels Lubr. 9(1):59-70, 2016, doi:10.4271/2016-01-0705.

[13] Georgios Karavalakis, Daniel Short, Diep Vu, Robert L. Russell et al., "The impact of ethanol and iso-butanol blends on gaseous and particulate emissions from two passenger cars equipped with spray-guided and wall-guided direct injection SI (spark ignition) engines,"

[14] M.A. Costagliola, L. De Simio, S. lannaccone, and M.V. Prati, "Combustion efficiency and engine out emissions of a S.I. engine fueled with alcohol/gasoline blends,"

[15] Arij Ben Amara, Toni Tahtouh, Elisabeth Ubrich, Laurie Starck et al., "Critical Analysis of PM Index and Other Fuel Indices: Impact of Gasoline Fuel Volatility and Chemical Composition," SAE Technical Paper.

[16] Butler, A.D., Sobotowski, R.A., Hoffman, G.J., and Machiele, P., "Influence of Fuel PM Index and Ethanol Content on Particulate Emissions from Light-Duty Gasoline Vehicles," SAE Technical Paper Series, SAE 2015 World Congress \& Exhibition, APR. 21, 2015, SAE International400 Commonwealth Drive, Warrendale, PA, United States, 2015.

[17] Chen, Z., Yang, F., Xue, S., Wu, Z. et al., "Impact of higher $n$-butanol addition on combustion and performance of GDI engine in stoichiometric combustion," Energy Conversion and Management 106:385-392, 2015, doi:10.1016/i.enconman.2015.09.051.

[18] Storey, J., Lewis, S., Szybist, J., Thomas, J. et al, "Novel Characterization of GDI Engine Exhaust for Gasoline and Mid-Level Gasoline-Alcohol Blends," SAE Int. J. Fuels Lubr. 7(2), 2014, doi:10.4271/2014-01-1606.

[19] J. Trost1, O. Laget, M. Cordier, F. Duffour et al., "Increasing Modern Spark Ignition Engine Efficiency: Optimization of intake ports dedicated to Miller cycle, high dilution and increased compression ratio," SIA Powertrain, International Conference and Exhibition, June 7 \& 8, 2017.

[20] Wallner, T., "Correlation Between Speciated Hydrocarbon Emissions and Flame Ionization Detector Response for Gasoline/Alcohol Blends," J. Eng. Gas Turbines Power 133(8):82801, 2011, doi:10.1115/1.4002893.

[21] Kalghatgi, G.T., Nakata, K., and Mogi, K., "Octane Appetite Studies in Direct Injection Spark Ignition (DISI) Engines," doi:10.4271/2005-01-0244.

[22] mittal, "Paper Number,"

[23] Miles, P., "Efficiency Merit Function for Spark Ignition Engines: Revisions and Improvements Based on FY16-17 Research," Technical Report. U.S. Department of Energy, Washington, DC. 2018., 102018th ed., 2018.

[24] Farrell, J.T., Holladay, J., and Wagner, R., "Co-Optimization of Fuels \& Engines: Fuel Blendstocks with the Potential to Optimize Future 
Gasoline Engine Performance; Identification of Five Chemical Families for Detailed Evaluation," 2018.

[25] Irimescu, A., Marchitto, L., Merola, S.S., Tornatore, C. et al., "Combustion process investigations in an optically accessible DISI engine fuelled with n-butanol during part load operation," Renewable Energy 77:363-376, doi:10.1016/i.renene.2014.12.029.

[26] Szybist, J.P. and Splitter, D.A., "Understanding chemistry-specific fuel differences at a constant RON in a boosted SI engine," Fuel 217:370-381, 2018, doi:10.1016/j.fuel.2017.12.100.

[27] Glaude, P.-A., Fournet, R., Bounaceur, R., and Molière, M., "Adiabatic flame temperature from biofuels and fossil fuels and derived effect on NOx emissions," Fuel Processing Technology 91(2):229-235, 2010, doi:10.1016/i.fuproc.2009.10.002.

[28] Burke, S., Ratcliff, M., McCormick, R., Rhoads, R. et al., "Distillation-based Droplet Modeling of Non-Ideal Oxygenated Gasoline Blends: Investigating the Role of Droplet Evaporation on PM Emissions," SAE Int. J. Fuels Lubr. 10(1):2017, doi:10.4271/2017-01-0581.

[29] Burke, S., Rhoads, R., Ratcliff, M., McCormick, R. et al., "Measured and Predicted Vapor Liquid Equilibrium of Ethanol-Gasoline Fuels with Insight on the Influence of Azeotrope Interactions on Aromatic Species Enrichment and Particulate Matter Formation in Spark Ignition Engines," SAE Technical Paper Series, WCX World Congress Experience, APR. 10, 2018, SAE International400 Commonwealth Drive, Warrendale, PA, United States, 2018.

[30] M. Koegl, B. Hofbeck, S. Will, and L. Zigan, "Investigation of soot formation and oxidation of ethanol and butanol fuel blends in a DISI engine at different exhaust gas recirculation rates,"

[31] Koichiro Aikawa, Takayuki Sakurai, and Jeff J. Jetter, "Development of a Predictive Model for Gasoline Vehicle Particulate Matter Emissions," 2015.
[32] Chapman, E., Winston-Galant, M., Geng, P., Latigo, R. et al., "Alternative Fuel Property Correlations to the Honda Particulate Matter Index (PMI)," SAE Technical Paper Series, SAE 2016 International Powertrains, Fuels \& Lubricants Meeting, OCT. 24, 2016, SAE International400 Commonwealth Drive, Warrendale, PA, United States, 2016.

[33] Eduardo J. Barrientos, James E. Anderson, M. Matti Maricq, and Andr? L. Boehman, "Particulate matter indices using fuel smoke point for vehicle emissions with gasoline, ethanol blends, and butanol blends,"

[34] Eduardo J. Barrientos, Magín Lapuerta, and André L. Boehman, "Group additivity in soot formation for the example of C-5 oxygenated hydrocarbon fuels,"

[35] Wittmann, J.-H. and Menger, L., "Novel Index for Evaluation of Particle Formation Tendencies of Fuels with Different Chemical Compositions," SAE Int. J. Fuels Lubr. 10(3), 2017, doi:10.4271/2017-01-9380.

[36] R. Ballesteros, J.J. Hernández, and J. Guillén-Flores, "Carbonyls speciation in a typical European automotive diesel engine using bioethanol/butanolâ€"diesel blends,"

[37] V.J. Feron, H.P. Til, Flora de Vrijer, R.A. Woutersen, F.R. Cassee and P.J. van Bladeren, "Aldehydes: occurrence, carcinogenic potential, mechanism of action and risk assessmennt," Mutation Research, 259 (1991) 363-385, 1990.

[38] J.R.Kuykendall, "Comprehensive Toxicology (Second Edition): 8.16 - Aldehydes," Comprehensive Toxicology 8, doi:10.1016/B978-0-08-046884-6.00916-7.

[39] Carter WPL, "Updated maximum incremental reactivity scale and hydrocarbon bin reactivities for regulatory applications: Prepared for California Air Resources Board Contract 07-339," 2010.

[40] Bin Hao, Chonglin Song, Gang Lv, Bo Li et al., "Evaluation of the reduction in carbonyl emissions from a diesel engine using Fischerâ€"Tropsch fuel synthesized from coal," 
